\title{
Effects of instantaneous groundwater availability on irrigated agriculture and implications for aquifer management
}

DOI:

10.1016/j.reseneeco.2019.101129

\section{Document Version}

Accepted author manuscript

Link to publication record in Manchester Research Explorer

Citation for published version (APA):

Rad, M. R., Brozovi, N., Foster, T., \& Mieno, T. (2019). Effects of instantaneous groundwater availability on irrigated agriculture and implications for aquifer management. Resource and Energy Economics, 101129. https://doi.org/10.1016/j.reseneeco.2019.101129

\section{Published in:}

Resource and Energy Economics

\section{Citing this paper}

Please note that where the full-text provided on Manchester Research Explorer is the Author Accepted Manuscript or Proof version this may differ from the final Published version. If citing, it is advised that you check and use the publisher's definitive version.

\section{General rights}

Copyright and moral rights for the publications made accessible in the Research Explorer are retained by the authors and/or other copyright owners and it is a condition of accessing publications that users recognise and abide by the legal requirements associated with these rights.

\section{Takedown policy}

If you believe that this document breaches copyright please refer to the University of Manchester's Takedown Procedures [http://man.ac.uk/04Y6Bo] or contact uml.scholarlycommunications@manchester.ac.uk providing relevant details, so we can investigate your claim.

\section{OPEN ACCESS}


1

2

\title{
Effects of Instantaneous Groundwater Availability on Irrigated Agriculture and Implications for Aquifer Management
}

\author{
Rad, M.R ${ }^{1, *}$, Brozovic, N. ${ }^{2}$, Foster, T. ${ }^{3}$, Mieno, T. ${ }^{4}$ \\ ${ }^{1}$ Department of Agricultural and Resource Economics, Colorado State University, Fort \\ Collins, CO, United States \\ ${ }^{2}$ Daugherty Water for Food Global Institute, University of Nebraska, Lincoln, NE, United \\ States \\ ${ }^{3}$ Department of Mechanical, Aerospace and Civil Engineering, University of Manchester, \\ Manchester, UK. \\ ${ }^{4}$ Department of Agricultural Economics, University of Nebraska-Lincoln, Lincoln, NE, \\ United States \\ *Mani.Rouhi_Rad@colostate.edu
}

\begin{abstract}
Groundwater is an important input for agricultural production in many parts of the world. Aquifer depletion has been shown to affect the rate that groundwater can be extracted from an aquifer. In this paper, we develop an analytical framework that accounts explicitly for the effects of limited instantaneous groundwater extraction rate (well capacity) on a producer's irrigation decisions. We show that limited well capacities can affect the producer's groundwater use and profit. We draw three important insights from these findings. First, we demonstrate that the price elasticity of demand for groundwater is higher for lower well capacities. Second, farmers' irrigation decisions are non-monotonic with respect to well capacity and climate conditions. Under a drier climate, producers with greater well capacities increase their groundwater use, and producers with lower well capacities reduce their water use. Third, through numerical analysis, we show that considering spatial heterogeneity in well capacities is important
\end{abstract}


for estimating the cost-effectiveness and distributional impacts of groundwater management policies. Our results shed new light on the importance of extraction capacity for groundwater management policies and the potential impacts of climate change on agricultural production.

\section{Introduction}

Groundwater is an important input for agricultural production in many parts of the world, but long-term food security in these areas is threatened by aquifer depletion. Understanding how biophysical systems affect producers' resource extraction decisions is critical for studying the consequences of resource depletion and designing effective resource management policies. In the case of groundwater, existing economics literature has mainly focused on changes in the marginal cost of pumping due to aquifer depletion as the main driver of changes in irrigation decisions (Gisser and Sanchez, 1980; Caswell and Zilberman, 1986; Knapp and Olson, 1995). An increase in the cost of pumping leads to a decrease in irrigation quantity, and at the aquifer level, external costs due to cost of pumping would create a wedge between the social planner and the competitive solution (Burness and Brill, 2001; Brozović et al., 2010; Guilfoos et al., 2013; Peterson and Saak, 2013). An implicit assumption in these studies is that well capacity is not binding and is homogenous across space. Well capacity is the upper bound on the amount of groundwater that can be extracted from an aquifer instantaneously without drying up the well. It is expressed in units of volume per time (e.g., gallons per minute). It is not a decision variable and is a function of physical aquifer characteristics such as transmissivity, storativity, and saturated thickness (Brookfield, 2016; Hecox et al., 2002). Limited well capacity may limit a farmer's ability to meet crop water demands fully during the growing season and, in particular, during droughts (Foster et al., 2015b). Declining well capacities are a direct consequence of aquifer depletion, and represent a key externality of pumping affecting groundwater irrigation decision-making (Foster et al., 2014; Sayre and Taraz, 2019; Ayres et al., 2018; Fishman, 2018; OECD, 2015; Hrozencik et al., 2017). With 
rapidly declining aquifer levels in many areas of the world, which can be intensified due to climate change, it is important to understand how limited well capacities will affect producer ability to manage production risks posed by climate variability and change.

In this study, we introduce a new analytical framework that incorporates well capacity to study the decision-making of a profit-maximizing farmer in terms of intensive (application rate per acre) and extensive (number of irrigated acres) margins of irrigation water use. We consider a system where extraction capacity can be a function of the state of the resource and is determined exogenously as a result of aquifer depletion. Rather than focusing on the optimal intra-seasonal irrigation decision making (Shani et al., 2004), this study focuses on the seasonal decisions of individuals (including irrigated acres and seasonal groundwater application), which are of the relevant time-scale for policy analysis. We further study the policy implications of our model for water pricing policies and the effects of climate change on groundwater use. Finally, using well-level data for a groundwater management area in Nebraska, we explore the effect of aquifer heterogeneity on the cost-effectiveness and distributional effects of different policies that intend to reduce groundwater extraction.

We provide three important results. First, we show that the price elasticity of demand for groundwater depends on extraction capacity. Producers with lower capacity wells may have a greater price elasticity of demand. Pricing resource use is one of the most discussed policies in resource economics. Our results highlight that similar pricing policies can potentially result in significantly different changes in groundwater use among producers in different regions of an aquifer due to the variation in the distribution of well capacities. Furthermore, declining aquifer levels can result in lower well capacities, changing the distribution of well capacities in a given region. Our results suggest that pricing policies may become more effective in reducing groundwater extraction when well capacities are lower. Second, we show that changes in groundwater demand can be non-monotonic with respect to well capacity under drier climatic conditions such that producers with greater well capacities can buffer against drier climates by increasing their water application while producers with lower capacity wells 
reduce their irrigated acres to be able to buffer against drier climatic conditions. Thus, in regions where climate change results in drier climatic conditions, there can be significant heterogeneity in the ability of producers in responding to these changes, which depends on their well capacities. Finally, since well capacity depends on aquifer characteristics and groundwater levels, considering instantaneous extraction capacity is important for studying the effects of aquifer depletion and the effectiveness of groundwater management policies. We find that second-best policies, such as pumping tax and water use quota, can have similar cost-effectiveness, i.e., they achieve the same reductions in groundwater use at similar costs. However, they can differ in their distributional implications. This can be very important in aquifers where there is significant heterogeneity in well capacities.

We contribute to the literature in three ways. First, while the concept of well capacity has been mentioned within the economics literature, the adopted modeling framework in these studies does not necessarily capture farmers' irrigation decisions under limited well capacities. For example, Burness and Brill (2001) model limited well capacity as an increase in pumping cost, while Wang and Nair (2013) consider it as a seasonal constraint on groundwater availability. These modeling approaches can result in unrealistic responses to changes in the cost of pumping or to groundwater pricing policies. For example, our analysis shows that in contrast to the case where there is a seasonal application limit, demand for groundwater is more elastic for those with lower well capacity. On the other hand, recent studies within the economics and water management literature have demonstrated the importance of considering well capacity for irrigation decisions of producers and for the effectiveness of groundwater management policies (Foster et al., 2014, 2015a, 2017a; Hrozencik et al., 2017; Manning and Suter, 2019). These studies use numerical analysis for specific cases, and their results may not hold generally. To our knowledge, no analytical model exists that characterizes producer decision making as a function of well capacities. Our analytical approach to considering well capacity allows us to explain the adjustment mechanisms of a producer to changes in well capacity. It also allows us to derive comparative statics with respect to changes in the price of water and climatic changes, which reveals the non-monotonic adjustment behavior 
of producers.

Second, the literature that studies the economics of fisheries and oil extraction has considered problems of stock-dependent extraction constraint that are similar to well capacity in groundwater extraction. For example, the fisheries literature has studied density-dependent catchability (Godø et al., 1999; Arreguín-Sánchez, 1996) in the case of pelagic fish species. On the other hand, in the case of oil extraction, Anderson et al. (2018) show that binding extraction capacity is important for studying optimal extraction decisions, and it is especially important to correctly consider margins of adjustment, such as drilling new wells. However, unlike oil reserves and fisheries where the marginal benefits are determined by the price of the marginal unit of resource extracted; groundwater is an input to a seasonal production process. Both seasonal groundwater application and instantaneous extraction capacity can affect (expected) crop yield. The production function developed in this study captures both of these effects and highlights the trade-off between irrigating an acre and applying more water per acre. Furthermore, the myopic decision making of producers in irrigated agriculture is different from the case of optimal extraction of mineral reserves. The model expands our understanding of the importance of extraction capacity on producer decisions under a seasonal production framework.

Finally, we add to the literature on heterogeneity in physical characteristics and their implications for policy (Caswell and Zilberman, 1986; Lichtenberg, 1989). Several studies on the economics of groundwater management have moved away from the representative farmer framework introduced by Gisser and Sanchez (1980). These studies (Feinerman and Knapp, 1983; Saak and Peterson, 2012; Guilfoos et al., 2016) have considered different sources of heterogeneity among producers, including land size and crop type, and have shown that different aquifer management policies could have different cost-effectiveness and distributional effects. Hrozencik et al. (2017) introduce well capacity as a source of heterogeneity in a hydro-economic framework. This paper adds well capacity as a source of heterogeneity in producer types within an analytical model. 


\section{Model}

At the beginning of a growing season, a farmer allocates irrigated acres (extensive margin of irrigation), A. Subsequently, during the growing season, the farmer must make decisions about when and how much irrigation to apply (intensive margin of irrigation) on each day of the growing season. Typically, intensive margin decisions are based on the current soil moisture level in the crop root zone (Vico and Porporato, 2011a), a strategy that can be optimal in terms of profit- and yield-maximization (Vico and Porporato, 2011b; Foster et al., 2014; Shani et al., 2004). Farmers condition each irrigation decision on both expected weather conditions, which affect irrigation requirements, and water supply constraints. Well capacity, $X$, defined as volume per day, together with irrigated area, determines the maximum irrigation application rate per acre per day, $\frac{X}{A}$, and, therefore, farmers' ability to maintain desired soil moisture levels. As a result, to simplify this process, we assume that a farmer simultaneously determines irrigated acres and the soil moisture target at the beginning of the season. The soil moisture target then determines the expected total amount of water applied per acre during the growing season, $u$. Higher soil moisture targets lead to more frequent irrigation events (and therefore higher expected seasonal irrigation), whereas lower soil moisture targets result in a lower irrigation frequency and a lower expected seasonal irrigation. $^{1}$

It is worth noting that our study focuses on irrigated acres and application rate per acre as the main decision variables ignoring other decisions such as crop choice and the choice of irrigation technology. Existing empirical studies (Hendricks and Peterson, 2012; Pfeiffer and Lin, 2014) suggest that these are the main decision variables in our context. For example, Pfeiffer and Lin (2014) find that changes in energy prices have a very small effect on the choice of crops.

\footnotetext{
${ }^{1}$ We assume that there is a one-to-one relationship between soil moisture target and expected seasonal application but not a one-to-one relationship between soil moisture target and actual seasonal application. The latter depends on the realization of weather.
} 
The model takes into account the seasonal and intra-seasonal nature of irrigation decisions within a seasonal framework. This is done by developing a production function that captures the effects of both seasonal water application and instantaneous groundwater availability on crop yield. The separable production function, $G\left(\frac{X}{A}, \epsilon\right) Z \Phi(u ; \epsilon, \theta)$, is composed of two parts. Assuming no limitations on instantaneous groundwater availability, $Z \Phi($.$) represents the$ relationship between the expected seasonal groundwater application per acre, $u$, and the expected crop yield. $Z$ is the maximum attainable expected crop yield under full irrigation. It essentially translates $\Phi$, which has a maximum of 1 , to actual crop yield units, e.g., bushels per acre. The function $\Phi($.$) follows a cumulative distribution function (CDF). The$ CDF has several advantages for describing the characteristics of the crop-water production relationship. First, the lower tail of the CDF function captures the fact that, in many production systems, there will be a minimum level of irrigation that must be applied before harvestable crop yield can develop (Rogers, 2015). Second, the upper tail of the CDF function captures the plateau of crop yield beyond which marginal revenue of additional water reaches zero (i.e., when the crop yield reaches its biophysical maximum) (English, 1990; English et al., 2002). Finally, it suggests that the marginal value of water is highest at some intermediate amount of water applied and not for the first or last units of water applied (Rogers, 2015; Schneekloth et al., 2009; Martin et al., 1984). Crop water demands and sensitivity to water stress varies significantly intra-seasonally and are greatest during periods of full crop development and crop yield formation (e.g., flowering and grain setting for a maize crop) (Rogers, 2015; Schneekloth et al., 2009; Martin et al., 1984). In these periods, it is critical that sufficient water is supplied, either from rainfall or irrigation, to meet crop water requirements in order to mitigate risks of yield reductions or even complete crop failure. As a result, the value of each unit of total seasonal irrigation is not constant in time. The value in the most sensitive growth stages will be significantly higher than in periods where growth and yields are less sensitive to water deficits (Andales, 2009).

The parameter $\epsilon$ in $\Phi(u ; \epsilon, \theta)$ captures how stochastic climate interacts with water application to affect crop yield. $\epsilon$ can be thought of as an index that captures long-term climatic changes. 
A higher $\epsilon$ corresponds to a drier climate, whereas a lower $\epsilon$ is characteristic of a wetter climate. The function suggests that in a drier climate, for a given well capacity and a given number of irrigated acres and soil moisture target, irrigation will be triggered more frequently and as a result, seasonal water requirements to achieve the same crop yield will be higher (Figure 1a). $\theta$ captures the distribution of crop yield for different amounts of water applied, holding other exogenous factors fixed. It shows the sensitivity of crop yield to deficit irrigation or intensive margin adjustments. As $\theta$ approaches zero, deficit irrigation will result in entirely losing crop yield. On the other hand, as $\theta \rightarrow \infty$ a producer can adjust on the intensive margin very easily as the production function becomes linear. $\Phi(u ; \epsilon, \theta)$ function can be thought of as the solution to the stochastic intra-seasonal optimization of the farmer, where each point along the function implicitly maps to a unique intra-seasonal soil moisture target strategy that maximizes expected crop yields for a given expected level of total seasonal irrigation.

We can write the properties of the CDF function in the region of profit-maximizing groundwater application per acre as $\Phi(u ; \epsilon, \theta) \in[0,1], \Phi_{1}(u ; \epsilon, \theta) \geq 0, \Phi_{11}(u ; \epsilon, \theta)<0, \Phi_{2}(u ; \epsilon, \theta) \leq 0$ and $\Phi_{12}(u ; \epsilon, \theta) \geq 0$ where $\Phi_{1}($.$) is the partial derivative of \Phi($.$) with respect to u$, while subscript 2 shows the partial derivative of $\Phi($.$) with respect to \epsilon$ and $\Phi_{12}($.$) shows the cross$ partial derivative of $\Phi($.$) with respect to u$ and $\epsilon$. These properties show that more water application increases crop yield at a decreasing rate, while for a given soil type and irrigation technology, a drier climate decreases crop yield for any amount of water application. Finally, under drier climates, the marginal benefit of adding a unit of water is greater. We normalize $Z$ to 1 for analytical simplicity. We relax this assumption in the numerical analysis.

Well capacity is dependent on physical aquifer characteristics, principally, transmissivity and storativity, which determine the amount of drawdown that occurs during pumping (Hecox et al., 2002). As an aquifer is depleted, saturated thickness, and therefore transmissivity, is reduced, leading to reductions in well capacities. These reductions, in turn, may limit farmers' ability to meet crop water demands fully during critical growth periods, resulting in 
crop water stress and loss of yield (Schneekloth and Andales, 2009). Declining well capacity is a physical consequence of aquifer depletion. As a result, conditional on crop types and technology choices, farmers' only available adaptation options are to reduce the amount of land that is irrigated, to maintain sufficient instantaneous water supply to the partial field area irrigated, or to reduce groundwater application per acre. Crop yield can thus be seen to be dependent on the potential irrigation application rate per acre per day (O'Brien et al., 2001; New and Fipps, 2000), which is equal to well capacity, $X$, divided by the number of irrigated acres, $A$. The required instantaneous application rate per acre per day depends on a crop's sensitivity to water stress. It would also be higher in dry years when both the total seasonal and the peak intra-seasonal crop water demands are at the highest level (Lamm, 2004; Lamm et al., 2007).

The second component of the production function, $G\left(\frac{X}{A}, \epsilon\right)$, captures the effect of instantaneous groundwater availability on crop yield response to seasonal irrigation inputs. It is a function of well capacity per acre per day, $\left(\frac{X}{A}\right)$. With a higher well capacity per acre per day, a farmer is able to meet crop water demand over the entire growing season for any weather conditions. With a lower well capacity per acre per day, for any soil moisture target, the farmer's ability to meet crop water demand during critical stages of the growing season in dry years decreases, resulting in lower expected crop yield for any expected seasonal water application. ${ }^{2}$ Effectively, well capacity constraints limit farmers' ability to allocate or schedule seasonal irrigation optimally during the growing season. As the climate gets drier, the negative effect of lower well capacities on expected crop yield increases (Figure 1b) because a drier climate increases the demand for water during the critical stages of the growing season and exacerbates the difference between peak crop water demand and the maximum application rate. Considering $\epsilon$ in both $G($.$) and \Phi($.$) is a novel feature of the$ model framework developed in this paper and underlines the important interactions between climate and aquifer conditions for determining farmers' ability to effectively manage crop

\footnotetext{
${ }^{2}$ Realistically, a lower well capacity means that more days pass between irrigation events to a specific acre on a field. Foster and Brozović (2018) show that assuming lower well capacities affect maximum application rate per acre per day results in qualitatively similar crop yields across the range of well capacities.
} 
production risks.

$G\left(\frac{X}{A}, \epsilon\right)$ can be thought of as a penalty function with a range of $[0,1)$. The properties of the $G($.$) function are: G_{1}\left(\frac{X}{A}, \epsilon\right) \geq 0, G_{11}\left(\frac{X}{A}, \epsilon\right) \leq 0, G_{2}\left(\frac{X}{A}, \epsilon\right) \leq 0$, and $G_{12}\left(\frac{X}{A}, \epsilon\right) \leq 0$ where $G_{1}($.$) and G_{11}($.$) are first and second partial derivatives with respect to \left(\frac{X}{A}\right), G_{2}($.$) is the$ first-order partial derivative with respect to $\epsilon$, and $G_{12}($.$) is the cross partial derivative of$ the $G$ function with respect to the maximum application rate per acre per day and climate. Finally, $G(0, \epsilon)=0$ and $\lim _{\frac{X}{A} \rightarrow \infty} G\left(\frac{X}{A}, \epsilon\right)=1$. These properties maintain that for very high maximum daily groundwater availability, the farmer can maintain sufficient soil moisture levels even during dry years and crop yield will not suffer. However, as the maximum daily availability of groundwater decreases, the effect of daily groundwater availability on expected crop yield increases at an increasing rate because the farmer is no longer able to meet crop water demand during the critical stages of the season when demand is highest and deficits have the greatest impacts on final yields. Equation 1 below shows a producer's problem of maximizing the expected profit by allocating irrigated acres and seasonal groundwater application per acre for a given climate:

$$
\begin{array}{ll}
\operatorname{Max}_{A, u} & \pi=A\left\{P G\left(\frac{X}{A}, \epsilon\right) \Phi(u ; \epsilon, \theta)-\Gamma(Y) u-K\right\} \\
\text { subject to } & A u \leq h(X) \\
A & \leq 1 \\
A, u \geq 0 &
\end{array}
$$

where $P$ is the price of crop output, $K$ shows the fixed costs of irrigation per acre that are independent of the quantity of groundwater applied. $Y$ is the saturated thickness of the aquifer and $\Gamma(Y)$ is the marginal cost of pumping a unit of water with $\Gamma^{\prime}(Y) \leq 0$, i.e., as aquifer levels decline, the marginal cost of pumping groundwater increases.

We make several simplifying assumptions. First, we assume that well capacity does not affect 
the cost of pumping. In practice, lower well capacities are correlated with higher pumping costs for two reasons. A lower well capacity for a given well is a result of the decline in the saturated thickness of the aquifer. The lower saturated thickness would also imply a deeper water table, which would result in a greater cost of pumping. Furthermore, with lower well capacity, a farmer needs to irrigate more hours to apply the same amount of water. Thus, the pumping cost can be higher. Also, at lower well capacities, pumps will operate less efficiently, increasing energy requirements, and there will also be more maintenance costs due to a greater running time of pumps. Adding increasing costs would not change the intuition behind our results significantly. Also, as mentioned in the previous section, saturated thickness affects well capacity. However, in this model, well capacity and saturated thickness are considered separately in order to explain the effects of instantaneous groundwater availability on irrigation decisions. ${ }^{3}$ Furthermore, we normalize the price of output to 1, i.e., $P=1$, so that cost is defined relative to the price of output, and $G\left(\frac{X}{A}, \epsilon\right) \Phi(u ; \epsilon, \theta)$ is revenue per acre. Thus, we remove $P$ from the rest of the analysis for notational simplicity. We use the actual prices and costs in the numerical analysis section. Finally, we normalize the total number of irrigated acres to 1 so that $A$ can also be interpreted as the proportion of irrigated acres. $h(X)$ is the maximum amount of groundwater available during the growing season and is a function of well capacity. It is the integral of the instantaneous amount of groundwater available over the season. ${ }^{4}$ The second constraint in equation 1 shows the limit on the proportion of the acres that can be irrigated, which is normalized to 1 . We set non-irrigated profits to zero. This is a simplification in the interest of analytical simplicity and does not affect results in a meaningful way. Given the basic model, we then provide the Lagrangian of the maximization problem:

\footnotetext{
${ }^{3}$ While changes in saturated thickness can predict changes of well capacity precisely, well capacity depends on other local unobservable characteristics of an aquifer and predicting well capacity can be difficult. As a result, it is important to understand the effect of well capacity separately and not only through the saturated thickness.

${ }^{4}$ In a simple way, it can be thought of as the number of days in a growing season times the maximum daily groundwater available. This is the case when well capacity does not decline during a single growing season, which is usually the case, for example in the American West. In a more general case, well capacity can decline during the season as groundwater is pumped out of the aquifer, for example in hard rock aquifers of India. However, we focus on the case where groundwater availability does not decline over the season.
} 


$$
\mathcal{L}=A\left\{G\left(\frac{X}{A}, \epsilon\right) \Phi(u ; \epsilon, \theta)-\Gamma(Y) u-K\right\}+\lambda_{1}[h(X)-A u]+\lambda_{2}[1-A]
$$

where $\lambda_{1}$ is the shadow value of adding one unit of water during the season by increasing well capacity and $\lambda_{2}$ is the shadow value of adding an irrigated acre. The first-order conditions are:

$$
\begin{aligned}
& \left\{G\left(\frac{X}{A^{*}}, \epsilon\right)-\left(\frac{X}{A^{*}}\right) G_{1}\left(\frac{X}{A^{*}}, \epsilon\right)\right\} \Phi\left(u^{*} ; \epsilon, \theta\right)-\Gamma(Y) u^{*}-K-\lambda_{1}^{*} u^{*}-\lambda_{2}^{*} \leq 0, \quad A^{*} \geq 0 \\
& A^{*}\left\{\left\{G\left(\frac{X}{A^{*}}, \epsilon\right)-\left(\frac{X}{A^{*}}\right) G_{1}\left(\frac{X}{A^{*}}, \epsilon\right)\right\} \Phi\left(u^{*} ; \epsilon, \theta\right)-\Gamma(Y) u^{*}-K-\lambda_{1}^{*} u^{*}-\lambda_{2}^{*}\right\}=0 \\
& A^{*}\left\{G\left(\frac{X}{A^{*}}, \epsilon\right) \Phi_{1}\left(u^{*} ; \epsilon, \theta\right)-\Gamma(Y)-\lambda_{1}^{*}\right\} \leq 0, \quad u^{*} \geq 0 \\
& A^{*} u^{*}\left\{G\left(\frac{X}{A^{*}}, \epsilon\right) \Phi_{1}\left(u^{*} ; \epsilon, \theta\right)-\Gamma(Y)-\lambda_{1}^{*}\right\}=0 \\
& h(X)-A^{*} u^{*} \geq 0, \quad \lambda_{1}^{*} \geq 0 \\
& \lambda_{1}^{*}\left\{h(X)-A^{*} u^{*}\right\}=0 \\
& 1-A^{*} \geq 0, \quad \lambda_{2}^{*} \geq 0 \\
& \lambda_{2}^{*}\left\{1-A^{*}\right\}=0
\end{aligned}
$$

where $A^{*}$ and $u^{*}$ are the profit-maximizing levels of extensive and intensive margin decisions for different well capacities and $\lambda_{1}^{*}$ and $\lambda_{2}^{*}$ are the profit-maximizing shadow values of the irrigation constraints. Equations 3, 4, 5, and 6 show the first-order conditions for irrigated acres, groundwater application per acre, shadow value of available water, and shadow value of irrigated acres. Since $A^{*}=0$ if and only if $u^{*}=0,{ }^{5}$ we only focus at the case where

\footnotetext{
${ }^{5}$ Note that $\mathrm{A}$ is the number of irrigated acres. If dryland production was considered, $1-A$ would be the
} 


$$
\begin{array}{r}
\left\{G\left(\frac{X}{A^{*}}, \epsilon\right)-\left(\frac{X}{A^{*}}\right) G_{1}\left(\frac{X}{A^{*}}, \epsilon\right)\right\} \Phi\left(u^{*} ; \epsilon, \theta\right)-\Gamma(Y) u^{*}-K-\lambda_{1}^{*} u^{*}-\lambda_{2}^{*}=0 \\
A^{*}\left\{G\left(\frac{X}{A^{*}}, \epsilon\right) \Phi_{1}\left(u^{*} ; \epsilon, \theta\right)-\Gamma(Y)-\lambda_{1}^{*}\right\}=0
\end{array}
$$

The first term in Equation 7a shows that keeping everything fixed, adding an acre increases profit due to production in one more irrigated acre, while it decreases profit because adding an acre would reduce the maximum daily application rate for the entire parcel. $\left\{G\left(\frac{X}{A^{*}}, \epsilon\right)-\right.$ $\left.\left(\frac{X}{A^{*}}\right) G_{1}\left(\frac{X}{A^{*}}, \epsilon\right)\right\}$ is always positive because $G($.$) is concave in the maximum application rate$ per acre per day, ${ }^{6}$ suggesting that the positive effect of adding an acre on crop production always outweighs its negative effects from daily groundwater availability. We suppress the star notation for the sake of notational simplicity.

In order to explain the effect of instantaneous groundwater availability on irrigation decisions over the domain of well capacity, $[0, \infty)$, we solve for $A$ and $u$ by decreasing well capacity from infinity to zero and provide the results in the form of propositions below. The first proposition provides the profit-maximizing decisions under infinite well capacity, which is the assumption underlying existing economics literature. The following proposition deviates from this condition by looking at well capacity rates less than infinity.

Proposition $1 .^{7}$ As $X \rightarrow \infty, A=1$ and $u=u_{\infty}(Y ; \theta, \epsilon){ }^{8}$

number of dryland acres.

${ }^{6}$ For the concave function, $G\left(\frac{X}{A}\right)$, marginal value is always less than the average value, i.e., $G^{\prime}\left(\frac{X}{A}\right) \leq \frac{G\left(\frac{X}{A}\right)}{\frac{X}{A}}$. As a result, $G\left(\frac{X}{A}\right)-\frac{X}{A} G^{\prime}\left(\frac{X}{A}\right)>0$.

${ }^{7}$ Proofs of the propositions are provided in Appendix A.

${ }^{8}$ Both propositions should be interpreted as conditional on $A, u>0$ and also, profits being greater than zero. Furthermore, our results are conditional on seasonal groundwater availability from well capacity not binding, i.e., $A u<h(X)$. 
This proposition suggests that there exists an optimal intensive margin allocation when a profit-maximizing farmer has access to unlimited instantaneous groundwater during the irrigation season. This condition is the case considered within the majority of the economics literature where the instantaneous groundwater availability does not affect crop yield, and pumping cost is the only factor affecting irrigation decisions.

The next proposition explains that with finite well capacity, instantaneous groundwater availability affects profit-maximizing irrigation decisions on the intensive and extensive margins.

Proposition 2. There exists a well capacity, $X_{s}$, where a profit-maximizing farmer would keep irrigated acres fixed and adjust per acre application rates for a marginal decline in well capacities at well capacities above $X_{s}$ and keep per acre application rates fixed and adjust irrigated acres for well capacities below $X_{s}$. We call this point the switching point.

The intuition here is that when well capacity decreases, a farmer's ability to meet crop water demand during critical stages of the growing season decreases. The farmer can reallocate water to other stages of the growing season while maintaining the same total seasonal application rate per acre. However, the marginal effect of irrigation is lower when irrigation is scheduled sub-optimally (Foster and Brozović, 2018). For high well capacities, the effect of daily groundwater availability is practically small because, for high well capacities, a small decrease in maximum daily groundwater availability only limits irrigation decisions on a small number of days resulting in minimal impacts on crop yields. ${ }^{9}$ As well capacity decreases, this effect becomes more significant. This suggests that where the saturated thickness is high, we do not expect to see significant changes in the intensive or extensive margins of irrigation decision as a result of aquifer depletion except through changes in pumping costs. However, it is important to note that extraction capacity may decline while significant saturated thickness remains when wells initially are drilled through only part of the full aquifer

\footnotetext{
${ }^{9}$ High well capacities are those above the switching point. They also depend on the type of crop, environment, etc.
} 
thickness. In this case, well capacities are recoverable, but would entail a significant cost for farmers through drilling deeper wells (e.g., as occurred during the recent drought in the California Central Valley). Importantly, the reduction in the amount of water application is not due to seasonal groundwater availability constraints, but rather because of the impact of the maximum daily groundwater availability on crop yield response to water and, therefore, optimal intensive margin irrigation decisions.

As well capacity decreases, the shadow value of adding an acre of irrigated land decreases. At $X_{s}(\theta, \epsilon, Y)$, the shadow value of adding an acre reaches zero. The intuition is that when well capacity decreases below $X_{s}$, further reductions in maximum daily application rates significantly affect crop yield because the producer is unable to maintain target soil moisture levels effectively during the growing season and is not able to meet crop water demand during the peak demand period. As a result, the farmer reduces the proportion of acres irrigated to avoid reducing the maximum daily application rate, $\frac{X}{A}$. The farmer will not decrease the maximum daily application rate and expected seasonal groundwater application per acre below this point. $X_{s}(\theta, \epsilon, Y)$ depends on the crop's sensitivity to seasonal and daily water availability, cost of pumping, and climate. A change in any of these factors can affect the switching point.

The existence of a switching point has two implications. First, a well capacity exists below which a profit-maximizing farmer does not further deficit irrigate with changes in well capacity (for a given climate, prices, and biophysical characteristics). A profit-maximizing producer chooses to adjust irrigated acres as a response to lower well capacities because limited instantaneous groundwater availability affects crop yield and profit. This is in contrast to the studies that do not consider instantaneous groundwater availability as a limitation on production and artificially set the intensive margin application rates (see, e.g., Burness and Brill (2001)). On the other hand, while our finding is similar to that of Wang and Nair (2013), it provides a different explanation for why we may observe adjustments of irrigated acres. 
Well capacity often varies among producers within an aquifer due to heterogeneity in physical aquifer characteristics such as conductivity and storativity. Furthermore, the base of the aquifer is usually not flat. Therefore, saturated thickness varies locally, even with consistent regional depletion trends. Proposition 2 suggests that, within an aquifer, aquifer depletion should affect farmers with lower well capacities more significantly, even if energy costs are fully subsidized, suggesting that the distribution of well capacities can be important for the effectiveness of aquifer management policies.

Together, Propositions 1 and 2 show the profit-maximizing levels of irrigated acres (extensive margin) and per acre application rate (intensive margin) over the domain of well capacity $X \in[0, \infty)$. Unlimited capacity or some variations of it are the cases considered within the existing economics literature. Comparing Proposition 2 to Proposition 1, we can conclude that instantaneous groundwater availability can affect irrigation decisions and profits nonlinearly. These results also provide us with a tractable analytical solution so that we can derive comparative statics.

Proposition 2 shows that, when production is sensitive to daily water availability, a switching point will always exist. However, it may also hold that a switching point will exist when production is insensitive to intra-seasonal water availability. For example, a switching point may also arise due to binding constraints on total seasonal water availability, as shown by Wang and Nair (2013). Their results can be considered a special case of the model studied in this paper when the crop is insensitive to daily water availability. A corollary to Propositions 1 and 2 is that whether seasonal groundwater allocations set by policy affect irrigation decisions depends on well capacity. Groundwater quotas (or allocations) are a common tool used to limit rates of aquifer depletion and associated pumping externalities. While setting a limit on seasonal water application can affect higher capacity wells, it may not affect low capacity wells. The reason is that farmers with low capacity wells reduce their irrigated acres to be able to meet the demand during the critical stages of the season and fewer irrigated acres result in smaller pumping volumes. This might be one possible explanation for why 
water allocation policies in western Kansas are not the binding constraint for many farmers. For example, in studying the significance of pumping externalities in western Kansas, Pfeiffer and Lin (2012) used a farmer's neighboring permit amount as an instrumental variable for determining their pumping quantity. They showed that while the pumping permit is a strong predictor of the amount of groundwater pumped, there is not a one-to-one relationship between them, and a one acre-foot increase in permit amount results in 0.3 acre-feet increase in quantity pumped.

Pricing resource use is one of the most discussed policies in resource economics. As shown in Propositions 1 and 2, limited well capacity affects the amount of groundwater that a profit-maximizing farmer will choose to pump. Well capacity, therefore, can influence the effectiveness of groundwater pricing policies that seek to reduce groundwater extraction. Well capacity is also important for studying the effects of climatic changes on irrigated agriculture across space and over time. Climatic changes could result in changes in seasonal and intraseasonal water availability in terms of precipitation (Fishman, 2018), which, in turn, will influence the amount of groundwater supply required to buffer crop growth against drought. Below, we provide two main comparative statics that can be derived from our analytical model with regard to the responsiveness of a producer to an increase in pumping cost and changes in climatic conditions.

Comparative Statics 1. ${ }^{10}$ An increase in pumping cost will decrease water consumption for every well capacity and will shift the switching point to a higher well capacity.

This result suggests that while high capacity wells adjust on the intensive margin as a result of an increase in pumping cost, medium and lower well capacities adjust on both the intensive and extensive margins. The range of well capacities for which a farmer will adjust their irrigated area depends on the size of the increase in pumping costs. The higher the cost, the greater the proportion of farmers that will reduce both irrigated acres and application per acre. A major implication of this finding is that the price elasticity of groundwater demand

\footnotetext{
${ }^{10}$ Proofs of the comparative statics are provided in Appendix B.
} 
depends on well capacity, and that elasticity will be higher for lower well capacities. The reason for dependence of price elasticity on well capacity is that producers with greater well capacities respond by only decreasing their intensive margin application rate, which is a small portion of their total water use. In contrast, farmers with lower well capacities respond by adjusting both the extensive and intensive margins, resulting in greater reductions to baseline water use.

Comparative Statics 2. The effect of drier climatic conditions on farmers' profit-maximizing groundwater use is non-monotonic with respect to climate conditions and well capacity.

In a drier climate, seasonal irrigation requirements are expected to increase, but peak daily water requirements (especially during sensitive growth stages) will also increase. As a result, in a drier climate, at any level of the maximum daily application rate, the expected crop yield is (weakly) lower. Consequently, drier climates will impact the expected crop yield response to irrigation through a combination of seasonal and intra-seasonal effects. From Proposition 2, we know that a producer with a high well capacity can irrigate their entire parcel at a profit-maximizing rate. From this proposition, we also know that the switching point depends on climatic conditions. Under drier climatic conditions, the switching point shifts to the right (i.e. higher well capacity is required to irrigate all available land). Furthermore, producers with high well capacities apply more groundwater on the intensive margin to buffer crops against drier climatic conditions. Producers with lower well capacities, however, need to adjust irrigated area to provide higher instantaneous irrigation capacity in order to effectively satisfy higher intra-seasonal crop water demands during critical growth stages in drier climates. In short, in a drier climate, the expected seasonal application is higher for a producer with a high well capacity, while the expected seasonal groundwater application is lower for a producer with a low well capacity. 


\section{Example: Groundwater Management in the High} Plains Region, USA

In this section, we apply Propositions 1 and 2 and Comparative Statics 1 and 2 to a case study of the Upper Republican Natural Resources District (URNRD) in southwest Nebraska. We first provide a background of the study area, underlying groundwater resources conditions and management conditions (including the distribution of well capacities) in the region. We then provide a description of the approach used to simulate relationships between irrigation inputs and crop yields in the region, and the choice of functional forms for functions $\Phi$ and $G$. We proceed to estimate the switching point for irrigated corn production in the region. Moreover, we study the effect of pumping cost change and climate change on groundwater application and the switching well capacity. Finally, we examine the cost-effectiveness of three different groundwater management policies that aim at reducing groundwater extraction. Particularly, we focus on the role of heterogeneous well capacities on distributional policy impacts and performances.

\subsection{Background}

The Upper Republican Natural Resources District (URNRD) in southwest Nebraska is within the Republican River Basin, which is one of the most highly regulated areas in the High Plains Aquifer with significant interest among local water managers to slow down aquifer depletion and to protect the Republican River from the impacts of groundwater-induced stream depletion. There are around 3,200 active agricultural wells with well capacities between 100 and 5,000 gallons per minute in the district. ${ }^{11}$ Well capacity data at the time the wells were drilled was obtained from the Nebraska Department of Natural Resources well database. The data used in this section are the ones reported at the time of well construction and may be higher than the current capacity of the well due to aquifer depletion. However, we note that

\footnotetext{
${ }^{11}$ The data is available publicly at https://dnr.nebraska.gov/data/groundwater-data.
} 
the decline in aquifer levels has been moderate in the region, and saturated thickness levels are relatively high. As a result, we do not expect major shifts in well capacity over time. Well capacities were then adjusted to actual well capacities using the equation provided in (Koester, 2004). ${ }^{12}$ Figure 2 shows the distribution of well capacities in the District. The average well capacity for the URNRD is $1475 \mathrm{gpm}$, while the standard deviation of well capacities is $765 \mathrm{gpm}$.

\subsection{Crop Water Production Modeling}

Crop-water production functions were first generated using a calibrated biophysical crop growth model. The specific model used was AquaCrop-OS (Foster et al., 2017b), an opensource version of the FAO AquaCrop model. AquaCrop-OS was chosen for use in this study due to its explicit focus on representing the effects of intra-seasonal water stress on crop development and yields, which are critical for determining reliable economic effects of irrigation water inputs and constraints. The model simulates daily crop development and soil water processes conditional on crop type, soil characteristics, daily weather inputs, and specified parameters representing the timing (i.e., soil moisture target) and constraints (i.e., daily maximum groundwater application rates) for irrigation management (Vanuytrecht et al., 2014; Steduto et al., 2009; Foster et al., 2017b). Importantly, specific to our chosen case study, AquaCrop-OS has also been successfully used in several studies to simulate corn yield response to water in the High Plains region (Heng et al., 2009; Foster et al., 2015a; Araya et al., 2017), along with in other agricultural regions of the United States such as California (Hsiao et al., 2009). Using parameters derived from these previous calibrated applications of the model for corn production in the High Plains, AquaCrop-OS was used to simulate yield response to water for a center-pivot irrigated corn crop, conditional on

\footnotetext{
${ }^{12}$ Reported well capacities are based on short duration pumping tests and can over-estimate pump rates. The Koester's equation adjusts reported pump rates to pump rates that are closer to actual pump rates during the season, based on empirical analysis. The equation is $X_{\text {koester }}=\frac{1.3842 X_{\text {reported }}}{(1+7.502310(-4)) X_{\text {reported }}}$ where $X_{\text {reported }}$ is the reported pump rate in the data and $X_{\text {Koester }}$ is the adjusted pump rate that we use in the analysis.
} 
weather and soil data for Chase County, Nebraska.

The weather data include the historical records of daily precipitation, maximum and minimum temperature, and reference evapotranspiration for a 30-year period (1985-2015) and were obtained from an observation station at Champion within the High Plains Regional Climate Centre AutomatedWeather Data Network. ${ }^{13}$ Soil hydraulic properties needed to run AquaCrop-OS, including saturated hydraulic conductivity and water content thresholds, were obtained from the USDA SSURGO soil database ${ }^{14}$ considering a loam soil type that is typical of soil conditions in SW Nebraska. For each year, simulations were run for multiple different potential soil moisture targets to generate a set of paired data points describing crop yields and total seasonal irrigation under each possible intra-seasonal irrigation strategy. Simulations were conducted conditional on a range of potential maximum daily per-acre irrigation application rates, which act as a proxy for well capacity within the model and control farmers' ability to maintain chosen soil moisture levels and avoid crop yield losses.

Subsequently, the production function proposed in Section 2 was fitted to the simulated average crop yield and average seasonal irrigation data points generated using AquaCropOS. The specific functional form adopted is $y_{d}+y_{m}\left(1-e^{(-\alpha+\epsilon) x}\right) \frac{1}{\theta \sqrt{2 \pi}} \int_{-\infty}^{u} e^{\frac{-(s-\epsilon)^{2}}{2 \theta^{2}}} d s$, where $y_{d}$ is the maximum attainable expected non-irrigated (dryland) crop yield, $y_{m}$ is the difference between the maximum attainable expected irrigated crop yield and non-irrigated yield given by AquaCrop-OS for historic weather conditions and unlimited instantaneous groundwater supply. $y_{d}$ and $y_{m}$ are fixed over time as they represent maximum dryland and irrigated attainable yields under the current (historic) climate. Together, $y_{d}$ and $y_{m}$ are equivalent to $Z$ in section $2 . \quad x=\frac{X}{A}$ is the maximum application rate per acre per day and $(1-$ $\left.e^{(-\alpha+\epsilon) x}\right)$ is the specific form of the $G$ function, and the functional form for the $\Phi$ function is $\frac{1}{\theta \sqrt{2 \pi}} \int_{-\infty}^{u} e^{\frac{-(s-\epsilon)^{2}}{2 \theta^{2}}} d s$ which is the normal CDF. These two functions were selected based on the properties mentioned in Section 2.

\footnotetext{
${ }^{13}$ data available here: https://hprcc.unl.edu/awdn.php

${ }^{14}$ data available here: https://websoilsurvey.sc.egov.usda.gov
} 
We assume that the maximum irrigable land is 130 acres which is the size of a typical quartersection center-pivot circle that represents the modal production system in the High Plains region. $y_{d}$ and $y_{m}$ were estimated directly from the simulated crop yield data. Specifically, $y_{d}$ is the average of simulated crop yield over the historical period (1985-2015) when irrigation is set to zero, and $y_{m}$ is the difference between average historical crop yields under full irrigation over the same period and $y_{d} . y_{m}$ is the expected gain in crop yield from full irrigation. The parameter values $\alpha, \epsilon$ and $\theta$ were then estimated simultaneously by fitting the functional form $y_{d}+y_{m}\left(1-e^{(-\alpha+\epsilon) x}\right) \frac{1}{\theta \sqrt{2 \pi}} \int_{-\infty}^{u} e^{\frac{-(s-\epsilon)^{2}}{2 \theta^{2}}} d s$ to AquaCrop output pairs of water use and crop yield for every daily application limit. The specific application limits used were 0.02 (0.5), 0.04 (1.0), 0.08 (2.0), $0.12(3.0), 0.16$ (4.0), 0.20 (5.0), 0.24 (6.0), $0.31(8.0), 0.39$ (10.0) and 0.79 (20.0) inches per day (mm per day). The estimates are presented in Table 1. For the analyses presented in next sections, we also assume a corn price of $\$ 4$ per bushel, a pumping cost of $\$ 8$ per acre-inch of groundwater and a $\$ 400$ fixed cost per acre. The next section provides an illustration for Propositions 1 and 2 at the well level.

\subsection{Switching Point}

In order to estimate the switching point and profit-maximizing values of irrigated acres, $A^{*}(X)$, and application rate per acre, $u^{*}(X)$, for every well capacity, $X$, we solve Equation 1 based on the fitted parametric production function (Table 1). Solving Equation 1 also provides us with seasonal groundwater application and profit.

Figure 3 shows that a switching point exists above which a profit-maximizing farmer irrigates the entire 130-acre parcel, while the number of irrigated acres decreases linearly below the switching point. Furthermore, below the switching point, groundwater application per acre stays constant. This suggests that, under the assumption that pumping costs remain fixed, a decrease in well capacity does not result in a further reduction in the intensive margin of groundwater application. Since adjusting irrigated acres results in a greater decrease in water use compared to adjusting the intensive margin, groundwater application decreases 
dramatically below the switching point as a result of lower well capacities. The responsiveness of water use and profits to well capacity is smaller above the switching point suggesting that below the switching point, there can be a significant loss in water use and profit from further reductions in well capacity. These results follow the intuition behind Propositions 1 and $2 .^{15}$ Interestingly, there are not many wells below the switching point in the URNRD for current climatic conditions (Figure 2), which suggests that we may mostly observe full quarter section circles in this region. Studies that use remote sensing data to study irrigated acres in the region support this observation (Deines et al., 2017). It is worth noting that the switching point also depends on the total number of irrigated acres available, i.e., if the 130-acre assumption is relaxed, the switching point would shift to the right. Effectively, the switching point represents the level of well capacity below which a farmer's irrigated area decision is no longer limited by land availability and is now constrained by well capacity.

\subsection{Effects of an Increase in Pumping Cost}

Comparative Statics 1 shows that an increase in pumping cost will decrease water consumption for every well capacity, and will shift the switching point to a higher well capacity. Figures $4 \mathrm{a}$ and $4 \mathrm{~b}$ show these results graphically. These figures show that a $\$ 1$ (or $12 \%$ ) increase in the cost of pumping shifts the switching point from 560 to $580 \mathrm{gpm}$. Under this price change, wells below 580 gpm reduce both irrigated acres and groundwater application per acre, while wells above this well capacity only adjust their groundwater application per acre. The results follow our expectation from Proposition 2 that the switching point is a function of the price of water. Furthermore, it shows that intensive margin decisions are dominant above the switching point. However, the intensive margin application below the switching point is also a function of prices and, as a result, an increase in the price of water results in both intensive and extensive margin adjustments.

\footnotetext{
${ }^{15}$ Including dryland profits can shift the switching point to the right. In general, as dryland profits relative to irrigated profits increase, the opportunity cost of irrigation increases and the switching point shifts to the right.
} 
As discussed in Comparative Statics 1, the price elasticity depends on well capacity, and it is higher for lower well capacities. This is shown graphically in Figure 4c. This is because producers with well capacities below 580 gpm reduce groundwater application on both the extensive and intensive margins in response to a marginal increase in the cost of water. However, it is worth noting that while lower well capacities have a higher elasticity of demand, they do not have the greatest response in terms of groundwater application to changes in the price of water. The reason is that wells with lower capacities use less groundwater for the baseline price, meaning that the gross water use reduction is smaller for very low well capacities compared to high well capacities.

Papers that study the price elasticity of demand for groundwater do not consider well capacity in their estimates (see, e.g., Hendricks and Peterson (2012); Pfeiffer and Lin (2014); Mieno and Brozović (2016); Bruno and Jessoe (2019)). Pfeiffer and Lin (2014) condition their estimates on the saturated thickness of the aquifer. Saturated thickness is correlated with well capacity. However, idiosyncratic factors, which are not captured by saturated thickness, can also influence well capacity. As a result, saturated thickness may not be a great proxy for well capacity in estimating the price elasticity of demand for groundwater. Not including well capacity directly in the regressions can provide biased estimates of the elasticity. Lower saturated thicknesses result in reduced well capacities. At the same time, reduced saturated thickness is associated with greater pumping lifts and thus higher pumping costs. As such, lower well capacity is often correlated with higher pumping costs. Empirical models should consider well capacity when attempting to estimate the responsiveness to changes in the cost of water due to aquifer depletion or pricing policies.

Dependence of the price elasticity of demand on well capacity has several important policy implications. First, it suggests that when considering water pricing policies, regulators should consider the heterogeneous effects of such policies due to differences in well capacity that affect the value of irrigation water in crop production. Considering the heterogeneity is especially important if well capacity is not correlated with depth to groundwater table. This 


\footnotetext{
${ }^{16}$ We have considered the case when the pumping cost is the same across producers. However, as explained earlier, the pumping cost is negatively correlated with the well capacity. Appendix C shows the sensitivity of the results in this section to a heterogenous pumping cost. Appendix $\mathrm{C}$ also shows the sensitivity of the switching point to other parameter values.
} 


\subsection{Effects of a Change in Climate Conditions}

In this section, we consider changes in average climatic conditions focusing on marginally drier climates or wetter climates. The graphical analysis in this section does not simulate a specific climate scenario for the region. The graphical results that use the numerical analysis of the characteristics of Chase County are shown in Figure 5. Numerical simulations of the effect of drier and wetter climates are done by setting $\epsilon=6.1$ for a drier climate and $\epsilon=4.1$ for a wetter climate. These values are selected to show the effects of a potentially drier or wetter climate on irrigation decisions and do not necessarily reflect the actual climate realizations.

From Proposition 2, we know that a producer with a high well capacity can irrigate the entire parcel and irrigate until the profit-maximizing point and that switching point depends on climatic conditions. Figure 5 shows that for drier climatic conditions the switching point shifts to the right. We also see that for high capacity wells, i.e., above $1027 \mathrm{gpm}$, producers apply more groundwater on the intensive margin to buffer for drier climatic conditions. ${ }^{17}$ Producers with well capacities below 1027 gpm, however, need to adjust their number of irrigated acres to provide higher instantaneous irrigation capacity, so that they can meet the higher peak crop water demands during the critical stages of the growing season in drier climates. In short, Figure 5 shows that in a drier climate, the expected seasonal application is higher for a producer with high well capacity, while expected seasonal groundwater application is lower for a producer with low well capacities.

These results have three implications for policy. First, climatic changes can result in further reductions in irrigated acres across the groundwater dependent areas such as the High Plains even if aquifer storage is held constant. Second, the effect of future climatic changes among farmers will depend on complex interactions between climate, aquifer conditions, and crop production risk that have been neglected in climate impact studies until recently (Fishman, 2018). While farmers with higher well capacities can buffer against the drier climatic con-

\footnotetext{
${ }^{17}$ Groundwater application for a wetter climatic condition is also presented for comparison.
} 
ditions, farmers with lower capacities may not have the same capability. Finally, this issue can be even more significant if aquifer levels and well capacities continue to decline in parts of the region. All producers may become more vulnerable to drier climatic conditions due to lower well capacities. Taking into account well capacity is thus important for understanding the interaction between aquifer depletion and climatic changes.

\subsection{Implications for Aquifer Management Policies}

An important application of the model developed in this paper is to develop an understanding of the cost-effectiveness of different policies that intend to reduce groundwater extraction and their effects across producers with different extraction capacities. With aquifer levels rapidly declining in many parts of the High Plains and other aquifers, there is significant demand from farmers and policymakers to reduce groundwater extraction from irrigated agriculture to either stabilize aquifer water levels in areas with higher recharge or extend the economic life of the aquifer in areas of lower recharge. Groundwater management seeks to address the common pool resource problem where the extraction rates of individual producers are different from those of a social planner. Aquifer management can provide incentives to reduce extraction rates to bring their groundwater use closer to the socially efficient levels. Due to the high costs of implementing heterogeneous policies to the regulator, most secondbest policies in practice are uniform across space and do not change over time (Guilfoos et al., 2016). In this section, we study three different policies for reducing groundwater extraction and compare them in terms of cost-effectiveness and their effects across different well capacities. The main focus of this section is on reducing extraction cost-effectively and we do not focus on spatial externalities of groundwater extraction. ${ }^{18}$

We consider three policies to reduce extraction:

\footnotetext{
${ }^{18}$ The goal of this section is not to find the social planner's allocation. The analysis here assumes that the optimal extraction rate is determined and intends to reduce extraction rates of the competitive solution to that of the social planner.
} 
1. Taxing a unit of groundwater (pumping tax);

2. Taxing an acre of irrigated land (occupation tax);

3. Limiting seasonal irrigation application based on farmers' profit-maximizing levels of groundwater application (water use quota)

The first policy charges producers based on the marginal unit extracted. Current rules in the URNRD mandate wells to have an approved flow meter installed. Flow meters make it possible to implement a tax on a unit of groundwater extracted. Similar policies have been implemented to reduce groundwater extraction (Smith et al., 2017). The second policy charges producers based on the number of acres they irrigate. Nebraska currently allows taxes of up to $\$ 10$ per irrigated acre (Aiken, 2012). The last policy reduces irrigation groundwater use by imposing a uniform percentage reduction across the producers. This policy assumes that producers initially apply groundwater at their profit-maximizing levels. The policy is similar to allocation policies used across the region (Drysdale and Hendricks, 2018). ${ }^{19}$

To simulate the effect of these policies on irrigation decisions and profits in the URNRD, we first maximize profits separately for each of the three policies. To do so, we divide the adjusted well capacities into bins of 1 acre-inch per day (18.8 gpm) which results in 63 bins and maximize profit for each bin. The equation below includes all three policies, i.e., pumping tax, $\tau_{W}$, occupation tax, $\tau_{A}$, and water use quota, $\eta_{W}$ :

$$
\begin{array}{ll}
\operatorname{Max}_{A, u} & \pi=A\left\{P G\left(\frac{X}{A}, \epsilon\right) \Phi(u ; \epsilon, \theta)-\Gamma(Y) u-\tau_{W} u-K-\tau_{A}\right\} \\
\text { subject to } & A u \leq \eta_{W} W^{*} \\
& A, u \geq 0
\end{array}
$$

\footnotetext{
${ }^{19}$ Our seasonal cap binds in expectation but in some years, water use could exceed the cap. Over time, average water use would fall below the cap. This reflects policies in regions with multi-year groundwater restrictions that e.g., restrict average water use over 5 years. If the cap could never be exceeded, producers would likely choose lower expected water use amounts than those modeled here.
} 
where $W^{*}$ is profit-maximizing water use under no policy. We then multiply water use and profits for each well capacity by the number of wells with that specific well capacity in the URNRD.

Since we are interested in the cost-effectiveness of these policies, we assume that the amount paid in taxes could be returned to the farmers in some way, e.g., through a lump-sum transfer back to the farmers. In this way, we only compare the policies based on their effect on profits due to a reduction in groundwater extraction rather than a combination of changes in productivity and taxes (Hendricks and Peterson, 2012).

Figure 6a shows the relationship between the reduction in groundwater extraction and profits for different policies at the district level. The decrease in groundwater application and profit occurs due to more strict policies, e.g., higher taxes or smaller quotas. As expected, the pumping tax is the cost-effective policy to reduce district-wide groundwater extraction as it targets extraction directly and allows for adjustments on both intensive and extensive margins. Based on Comparative Statics 1 and Section 3.4, an increase in pumping cost mainly results in adjustments on the intensive margin for wells with high capacity. The distribution of well capacities within the URNRD is skewed towards higher rates and above the switching point. Under these conditions, acreage-based policies will be significantly less cost-effective than the pumping cost. ${ }^{20}$ Finally, a water use quota also results in costs that are close to the pumping tax for any amount of reduction in district-level groundwater use. $^{21}$

The vertical line in Figure 6a shows the loss of profit associated with a $20 \%$ reduction in the district-level groundwater pumping for each policy. The loss of profit from reducing groundwater extraction by $20 \%$ is about $\$ 5.8$ million for the pumping tax policy, while it is

\footnotetext{
${ }^{20}$ Numerical analysis shows that for a distribution of well capacities centered below the switching point, the costs of acreage-based policies and the pumping tax are very similar.

${ }^{21}$ Given that our production function was generated assuming no cap on the amount of groundwater application, there could be an additional opportunity cost for groundwater application with the seasonal cap and, as a result, the profit-maximizing producer may reallocate groundwater application during the season. This could happen for example if a producer changes their soil moisture target in response to the cap. Our assumption may result in over-estimating the costs of a water use quota policy.
} 
$\$ 6.3$ million, $\$ 14$ million for water use quota, and occupation tax respectively. Figures $6 \mathrm{~b}$ and 6c show the changes in farm-level groundwater application and profits for the $20 \%$ reduction compared to the status quo of no policy. As noted earlier, under the pumping tax, producers with higher capacity wells respond by reducing their intensive margin application while those with lower well capacities reduce both irrigated acres and per acre groundwater application. Furthermore, an increase in the cost of pumping shifts the switching point to a higher well capacity (Comparative Statics 1 and Section 3.4). Reduction in groundwater extraction peaks at $540 \mathrm{gpm}$ which is the switching point under the status quo. Wells at the switching point irrigate the entire parcel at the baseline and as a result of the policy reduce both their intensive and extensive margin applications and have the largest reduction in groundwater application. Under the occupation tax, irrigating every acre remains profitable for higher capacity wells. However, wells below 1,100 gpm will reduce their irrigated acres and, as a result, groundwater application. Similar to the pumping tax, the reduction peaks at the switching point under the status quo. Under this policy, most of the overall reduction comes from the intermediate and low capacity wells. Under the water use quota policy, limiting water use affects groundwater application proportional to application under the baseline. Producers with higher capacity wells irrigate more acres and apply more groundwater under the status quo as discussed in Proposition 2. As a result, under this policy, the reduction in groundwater application is greater for higher well capacities.

From a policy perspective, these results are important for several reasons. First, among the two water use-based policies, i.e., pumping tax and water use quota, aquifer-level costs are very similar (Figure 6a). However, these policies have very different distributional effects. A pumping tax affects producers with intermediate wells more significantly while a water use quota policy results in a more uniform reduction in water use across well capacities. Distributional effects of different policies across producers are important because policies with a negative effect on many farmers may be difficult to implement because they will be perceived to be inequitable (Guilfoos et al., 2016). 


\footnotetext{
${ }^{22}$ In the case of the URNRD, we reject the null of no spatial autocorrelation in well capacities using the Moran's I statistic which is positive in our case.
} mainly due to the fact that adjustments on the extensive margins are very costly relative to adjustments on the intensive margin. Consequently, this policy results in costly adjustments for producers with well capacities around the switching point. This comparison is related to the discussion on prices and quantities (Weitzman, 1974). Our findings suggest that while in general taxes are more cost-effective than second-best quotas, such results may not hold when comparing these policies on different margins.

Third, while we have considered the case where extracting a unit of water has the same marginal damage or externality, this may not always be the case in reality. For example, there is a spatial correlation in physical aquifer characteristics including well capacity. ${ }^{22}$ Areas with low saturated thicknesses generally are associated with low well capacities, whereas areas with high saturated thicknesses typically have higher well capacities. As a result, marginal damages or externalities may depend on aquifer levels and on well capacities. Areas with greater saturated thickness include more wells. However, changes in aquifer levels result in smaller externalities. On the other hand, areas with lower saturated thickness include fewer wells but the marginal impact of a change in aquifer levels could be larger in those areas. Similarly, well capacity could be correlated with soil type where areas with sandy soil types have a greater demand for groundwater and pumping externalities could be larger in these areas. Figures $6 \mathrm{~b}$ and $6 \mathrm{c}$ show that in the case where marginal damages or externalities of low capacity wells are larger than that of high capacity wells, a uniform acreage tax may be preferred to a uniform pumping tax because an acreage tax results in greater reductions in water use from the lower capacity wells. Of course, this will also result in larger profit losses for low capacity wells and the trade-off between profits and externalities become important.

Finally, Figure 6b also provides some insight into the performance of a potential groundwater market. For example, a well functioning thick market with a cap set at $80 \%$ of current

Second, a water use quota policy is more cost-effective than the occupation tax. This is 
extraction rates, will reach the same allocation at the equilibrium as the tax values in Figure 6b. Figure 6b suggests that for a groundwater market where groundwater rights are defined based on the quantity of water extracted if the permits are allocated equally among producers, we expect those with high capacity wells to be the buyers and farmers with low capacity wells to be the sellers. This mechanism can potentially reallocate groundwater from areas low saturated thickness and low capacity to areas of the aquifer with higher saturated thickness and higher well capacity, which could result in larger aquifer depletion rates at a regional scale. On the other hand, if the groundwater permits are defined based on the number of acres irrigated, we expect farmers with high capacity wells and farmers with low capacity wells to be the sellers, and farmers with intermediate well capacity to be the buyers in the market. This information can be very useful in understanding the ex-ante performance of markets and can help to define property rights depending on the goal of policymakers. Policymakers should also pay attention to the distribution of the wells and the type and distribution of groundwater rights within the district in determining whether a groundwater market can be an appropriate choice.

\section{Discussion}

Existing models in the economics literature do not consider limited extraction capacity for groundwater from an aquifer and, as a result, assume a homogeneous demand function and a uniform response among different types of producers. We show that considering instantaneous extraction capacity of groundwater is important for understanding irrigation decisions and that overlooking extraction capacity could result in miscalculating the effectiveness of groundwater policies and potential impacts of climate change. The analytical results show that there exists a switching point in the decision making of a profit-maximizing producer which is a function of crop choice, climate, irrigation technology, and prices. For well capacities greater than the switching point, a profit-maximizing farmer can irrigate their entire parcel while adjusting water use solely on the intensive margin as well capacity changes. A 
profit-maximizing farmer with a lower well capacity than the switching point, however, will adjust irrigated acres (extensive margin) to ensure a sufficient instantaneous groundwater capacity to meet crop water demands during the critical periods of the growing season.

A major finding of our study is that, theoretically, the price elasticity of demand should depend on well capacity. For lower well capacities price elasticity of demand is higher because of the adjustment on both intensive and extensive margins. Ignoring well capacity can result in biased estimates of the price elasticity of demand for groundwater. However, from the policy perspective, we should note that baseline groundwater use is also lower for lower well capacities. Given that aquifer depletion could shift the distribution of well capacities towards lower values, groundwater pricing policies could become more costly under further aquifer depletion. Furthermore, this result highlights the importance of considering the state of the aquifer for groundwater pricing policies.

Our results also suggest that considering both seasonal and intra-seasonal effects of water availability on crop yield is important for understanding the effect of climate change across well capacities and understanding the effect of aquifer depletion under drier climates. We show that under drier climatic conditions, while producers with higher well capacities can increase extraction and "buffer" for the effects of drier climatic conditions, producers with lower well capacities may reduce their groundwater use on both the intensive and extensive margins which result in loss of profit. Since aquifer depletion can result in lower well capacities, these results suggest that impacts of climate change can not be understood adequately without considering simultaneous projected changes in aquifer water levels that will, in turn, impact distributions of well capacities amongst producers.

The results of the policy analysis show that, while a uniform pumping tax is the cost-effective policy to reduce irrigation, the majority of water use reduction comes from high capacity wells. On the other hand, a reduction in groundwater extraction from a uniform acreage tax primarily comes from intermediate and low capacity wells. In cases where targeting low capacity wells provides higher benefits for the aquifer a uniform acreage tax might be the 
preferred policy. However, in cases where higher capacity wells cause larger externalities, a uniform pumping tax might be the preferred policy. These findings demonstrate that groundwater supply constraints imposed by well capacity are an important determinant of farmer water use decisions (in particular irrigated acreage) and aquifer policy effectiveness.

The results of the model studied in this paper are also consistent with trends of irrigated acres and well capacities in the High Plains region. While our study area in Nebraska has not experienced major changes in aquifer levels and well capacities over time, in other regions of the aquifer, saturated thickness levels have changed significantly. For example, Figure 7 shows that since 1995 aquifer levels and well capacities in portions of the High Plains Aquifer in Kansas, where groundwater is the predominant source of irrigation, have continued to decline. At the same time, irrigated acres have also followed a decreasing trend. This is despite the fact that crop prices have generally followed an increasing pattern over this time period. While Edwards (2016) shows that the creation of the groundwater management districts in Kansas in 1972 has affected the size of the farmlands, our model also presents one possible explanation for how declining well capacity might lead to lower irrigated acreages.

Furthermore, the diversity of the policies used for managing groundwater extraction in different regions across the High Plains Aquifer raises the question of whether underlying geophysical factors play a role in affecting the type of policies selected. Our results show that, for the case of the Upper Republican Natural Resources District in Nebraska, the pumping tax and water use quota policies can have the same cost-effectiveness, but may result in a significantly different distribution of costs and benefits across producers. Since local support from farmers is important for the successful implementation of aquifer management policies, local distribution of well capacities, therefore, may have played a role in policy outcomes.

Future research can extend our study in several ways. First, our results suggest that the buffer value of aquifer against dry weather conditions depends on saturated thickness. The 
existing economic research, which does not consider instantaneous groundwater availability (Tsur, 1990; Gemma and Tsur, 2007), may provide biased estimates for the buffer value of aquifers, i.e., they may over-estimate the buffer value of aquifer when saturated thickness is low and thus underestimate the value of aquifer management when the buffer value of aquifer is still high. Future research should study the buffer value of aquifer considering well capacity in more depth.

Second, Provencher and Burt (1993) argue that three types of pumping externalities exist: a stock externality, which is a reduction in the stock of available groundwater for future pumping for other producers, a pumping cost externality, which increases the cost of pumping for other producers, and a risk externality, which increases the risk of production due to lower groundwater stock levels. Their definition of the risk externality is related to the concept of well capacity as they argue that pumping one unit of groundwater will increase production risk for all other producers. However, in their specification of production risk, the stock of groundwater is considered only as the total volume of groundwater storage so that risk is a result of changes in the volume of groundwater available. As a result, in their model groundwater stock only affects the profits in the final year of aquifer life where a limited volume of groundwater is available. Our study suggests that the definition of risk externality introduced by Provencher and Burt can be broadened to include the increase in production risk as a result of declining extraction capacities. Future research could further investigate the magnitude of the risk externality considering the effect of instantaneous groundwater availability on crop yield and the effect of saturated thickness on well capacity.

Third, although this study does not include a dynamic model, our results provide insight into potential temporal and spatial benefits of aquifer management. These results are important for the temporal value of aquifer management when we consider that as aquifer levels decline, well capacities decline (Brookfield, 2016; Hecox et al., 2002). The results suggest that an increase in pumping cost is not the only effect on irrigation decisions and that the demand function throughout the life of the aquifer will not be the same as assumed in earlier models 
such as Gisser and Sanchez (1980), and is nonlinear. Also, the decline in well capacity means that the future distribution of well capacities may not be the same. As a result, the distribution of profits within the aquifer management district or basin could change over time. Future research could study the changes in the distribution of well capacities on the effectiveness of aquifer management policies using dynamic models. 


\section{References}

Aiken, J. D. (2012). Water management funding issues. Cornhusker Economics. University of Nebraska Lincoln.

Andales, A. A. (2009). Effects of weather on irrigation requirements. Irrigation Fact Sheet No. 4.721. Colorado State University Extension.

Anderson, S. T., Kellogg, R., and Salant, S. W. (2018). Hotelling under pressure. Journal of Political Economy, 126(3):984-1026.

Araya, A., Kisekka, I., Vara Prasad, P., and Gowda, P. (2017). Evaluating optimum limited irrigation management strategies for corn production in the Ogallala Aquifer region. Journal of Irrigation and Drainage Engineering, 143(10):04017041.

Arreguín-Sánchez, F. (1996). Catchability: a key parameter for fish stock assessment. Reviews in fish biology and fisheries, 6(2):221-242.

Ayres, A. B., Edwards, E. C., and Libecap, G. D. (2018). How transaction costs obstruct collective action: The case of california's groundwater. Journal of Environmental Economics and Management, 91:46 - 65 .

Brookfield, A. (2016). Minimum saturated thickness calculator. Kansas Geological Survey Open-File Report, 3.

Brozović, N., Sunding, D. L., and Zilberman, D. (2010). On the spatial nature of the groundwater pumping externality. Resource and Energy Economics, 32(2):154-164.

Bruno, E. M. and Jessoe, K. (2019). Water Markets and Climate Change Adaptation: Micro-level Evidence on Agricultural Water Demand. Working paper.

Burness, H. S. and Brill, T. C. (2001). The role for policy in common pool groundwater use. Resource and Energy Economics, 23(1):19-40. 
Caswell, M. F. and Zilberman, D. (1986). The effects of well depth and land quality on the choice of irrigation technology. American Journal of Agricultural Economics, 68(4):798811.

Deines, J. M., Kendall, A. D., and Hyndman, D. W. (2017). Annual irrigation dynamics in the US Northern High Plains derived from Landsat satellite data. Geophysical Research Letters, 44(18):9350-9360.

Drysdale, K. M. and Hendricks, N. P. (2018). Adaptation to an irrigation water restriction imposed through local governance. Journal of Environmental Economics and Management, 91:150-165.

Edwards, E. C. (2016). What lies beneath? Aquifer heterogeneity and the economics of groundwater management. Journal of the Association of Environmental and Resource Economists, 3(2):453-491.

English, M. (1990). Deficit irrigation. I: Analytical framework. Journal of Irrigation and Drainage Engineering, 116(3):399-412.

English, M. J., Solomon, K. H., and Hoffman, G. J. (2002). A paradigm shift in irrigation management. Journal of Irrigation and Drainage Engineering, 128(5):267-277.

Feinerman, E. and Knapp, K. C. (1983). Benefits from groundwater management: magnitude, sensitivity, and distribution. American Journal of Agricultural Economics, $65(4): 703-710$.

Fishman, R. (2018). Groundwater depletion limits the scope for adaptation to increased rainfall variability in India. Climatic Change, 147(1-2):195-209.

Foster, T. and Brozović, N. (2018). Simulating crop-water production functions using crop growth models to support water policy assessments. Ecological Economics, 152:9-21.

Foster, T., Brozović, N., and Butler, A. (2015a). Analysis of the impacts of well yield and groundwater depth on irrigated agriculture. Journal of Hydrology, 523:86-96. 
Foster, T., Brozović, N., and Butler, A. (2015b). Why well yield matters for managing agricultural drought risk. Weather and Climate Extremes, 10:11-19.

Foster, T., Brozović, N., and Butler, A. (2017a). Effects of initial aquifer conditions on economic benefits from groundwater conservation. Water Resources Research, 53(1):744762.

Foster, T., Brozović, N., Butler, A., Neale, C., Raes, D., Steduto, P., Fereres, E., and Hsiao, T. C. (2017b). Aquacrop-OS: An open source version of FAO's crop water productivity model. Agricultural Water Management, 181:18-22.

Foster, T., Brozovic, N., and Butler, A. P. (2014). Modeling irrigation behavior in groundwater systems. Water Resources Research, 50(8):6370-6389.

Gemma, M. and Tsur, Y. (2007). The stabilization value of groundwater and conjunctive water management under uncertainty. Applied Economic Perspectives and Policy, $29(3): 540-548$.

Gisser, M. and Sanchez, D. A. (1980). Competition versus optimal control in groundwater pumping. Water Resources Research, 16(4):638-642.

Godø, O., Walsh, S., and Engås, A. (1999). Investigating density-dependent catchability in bottom-trawl surveys. ICES Journal of Marine Science, 56(3):292-298.

Guilfoos, T., Khanna, N., and Peterson, J. M. (2016). Efficiency of viable groundwater management policies. Land Economics, 92(4):618-640.

Guilfoos, T., Pape, A. D., Khanna, N., and Salvage, K. (2013). Groundwater management: The effect of water flows on welfare gains. Ecological Economics, 95:31-40.

Haacker, E. M., Kendall, A. D., and Hyndman, D. W. (2016). Water level declines in the High Plains Aquifer: Predevelopment to resource senescence. Groundwater, 54(2):231-242. 
Hecox, G., Macfarlane, P., and Wilson, B. (2002). Calculation of yield for High Plains wells: Relationship between saturated thickness and well yield. Kansas Geological Survey Open File Report, 24.

Hendricks, N. P. and Peterson, J. M. (2012). Fixed effects estimation of the intensive and extensive margins of irrigation water demand. Journal of Agricultural and Resource Economics, pages 1-19.

Heng, L. K., Hsiao, T., Evett, S., Howell, T., and Steduto, P. (2009). Validating the FAO AquaCrop model for irrigated and water deficient field maize. Agronomy Journal, 101(3):488-498.

Hrozencik, R., Manning, D., Suter, J., Goemans, C., and Bailey, R. (2017). The heterogeneous impacts of groundwater management policies in the Republican River Basin of Colorado. Water Resources Research, 53(12):10757-10778.

Hsiao, T. C., Heng, L., Steduto, P., Rojas-Lara, B., Raes, D., and Fereres, E. (2009). AquaCrop - the FAO crop model to simulate yield response to water: III. Parameterization and testing for maize. Agronomy Journal, 101(3):448-459.

Knapp, K. C. and Olson, L. J. (1995). The economics of conjunctive groundwater management with stochastic surface supplies. Journal of Environmental Economics and Management, 28(3):340-356.

Koester, P. (2004). Nebraska irrigation computations for the RRCA groundwater model. Republican River Compact, Nebraska, USA.

Lamm, F. (2004). Corn production as related to sprinkler irrigation capacity. In Proceedings of the Central Plains Irrigation Conference, Kearney, Nebraska, pages 23-36.

Lamm, F., Stone, L., and O'brien, D. (2007). Crop production and economics in Northwest Kansas as related to irrigation capacity. Applied Engineering in Agriculture, 23(6):737-745. 
Lichtenberg, E. (1989). Land quality, irrigation development, and cropping patterns in the Northern High Plains. American Journal of Agricultural Economics, 71(1):187-194.

Manning, D. T. and Suter, J. F. (2019). Production externalities and the gains from management in a spatially-explicit aquifer. Journal of Agricultural and Resource Economics.

Martin, D., Supalla, R., McMullen, B., and Nedved, S. (2007). Water optimizer, a decision support tool for producers with limited water. University of Nebraska-Lincoln Departments of Biological Systems Engineering and Agricultural Economics, Lincoln, Nebraska.

Martin, D. L., Dorn, T. W., Melvin, S. R., Corr, A. J., and Kranz, W. L. (2011). Evaluating energy use for pumping irrigation water. In Proceedings of the 23rd Annual Central Plains Irrigation Conference, pages 22-23.

Martin, D. L., Watts, D. G., and Gilley, J. R. (1984). Model and production function for irrigation management. Journal of irrigation and drainage engineering, 110(2):149-164.

Mieno, T. and Brozović, N. (2016). Price elasticity of groundwater demand: Attenuation and amplification bias due to incomplete information. American Journal of Agricultural Economics, 99(2):401-426.

New, L. and Fipps, G. (2000). Center pivot irrigation. Texas Agricultural Extension Service - The Texas A\&M University System. Bulletin B-6096, page 20.

O'Brien, D., Lamm, F., Stone, L., and Rogers, D. (2001). Corn yields and profitability for low-capacity irrigation systems. Applied Engineering in Agriculture, 17(3):315.

OECD (2015). Drying wells, rising stakes: Towards sustainable agricultural groundwater use.

Peterson, J. M. and Saak, A. E. (2013). Spatial externalities in aquifers with varying thickness: Theory and numerical results for the Ogallala Aquifer. In Agricultural and Applied Economics Association Annual Meeting, Washington DC. 
Pfeiffer, L. and Lin, C.-Y. C. (2012). Groundwater pumping and spatial externalities in agriculture. Journal of Environmental Economics and Management, 64(1):16-30.

Pfeiffer, L. and Lin, C.-Y. C. (2014). The effects of energy prices on agricultural groundwater extraction from the High Plains Aquifer. American Journal of Agricultural Economics, 96(5):1349-1362.

Provencher, B. and Burt, O. (1993). The externalities associated with the common property exploitation of groundwater. Journal of Environmental Economics and Management, $24(2): 139-158$.

Rogers, D. H. (2015). Agricultural crop water use. Kansas State University. Agricultural Experiment Station and Cooperative Extension Service; 934.

Saak, A. E. and Peterson, J. M. (2012). Groundwater pumping by heterogeneous users. Hydrogeology Journal, 20(5):835-849.

Sayre, S. S. and Taraz, V. (2019). Groundwater depletion in India: Social losses from costly well deepening. Journal of Environmental Economics and Management, 93:85-100.

Schneekloth, J. P. and Andales, A. A. (2009). Seasonal water needs and opportunities for limited irrigation for Colorado crops. Colorado State University Extension.

Schneekloth, J. P., Bauder, T. A., and Hansen, N. C. (2009). Limited irrigation management: Principles and practices. Colorado State University Extension.

Shani, U., Tsur, Y., and Zemel, A. (2004). Optimal dynamic irrigation schemes. Optimal Control Applications and Methods, 25(2):91-106.

Smith, S. M., Andersson, K., Cody, K. C., Cox, M., and Ficklin, D. (2017). Responding to a groundwater crisis: The effects of self-imposed economic incentives. Journal of the Association of Environmental and Resource Economists, 4(4):985-1023. 
Steduto, P., Hsiao, T. C., Raes, D., and Fereres, E. (2009). AquaCrop-The FAO crop model to simulate yield response to water: I. Concepts and underlying principles. Agronomy Journal, 101(3):426-437.

Tsur, Y. (1990). The stabilization role of groundwater when surface water supplies are uncertain: The implications for groundwater development. Water Resources Research, 26(5):811-818.

Vanuytrecht, E., Raes, D., Steduto, P., Hsiao, T. C., Fereres, E., Heng, L. K., Vila, M. G., and Moreno, P. M. (2014). AquaCrop: FAO's crop water productivity and yield response model. Environmental Modelling \& Software, 62:351-360.

Vico, G. and Porporato, A. (2011a). From rainfed agriculture to stress-avoidance irrigation: I. A generalized irrigation scheme with stochastic soil moisture. Advances in Water Resources, 34(2):263-271.

Vico, G. and Porporato, A. (2011b). From rainfed agriculture to stress-avoidance irrigation: II. Sustainability, crop yield, and profitability. Advances in Water Resources, 34(2):272281.

Wang, C. and Nair, S. (2013). The economics of deficit irrigation. Natural Resource Modeling, 26(3):331-364.

Weitzman, M. L. (1974). Prices vs. quantities. The review of economic studies, 41(4):477491. 


\section{$5 \quad$ Figures and Tables}

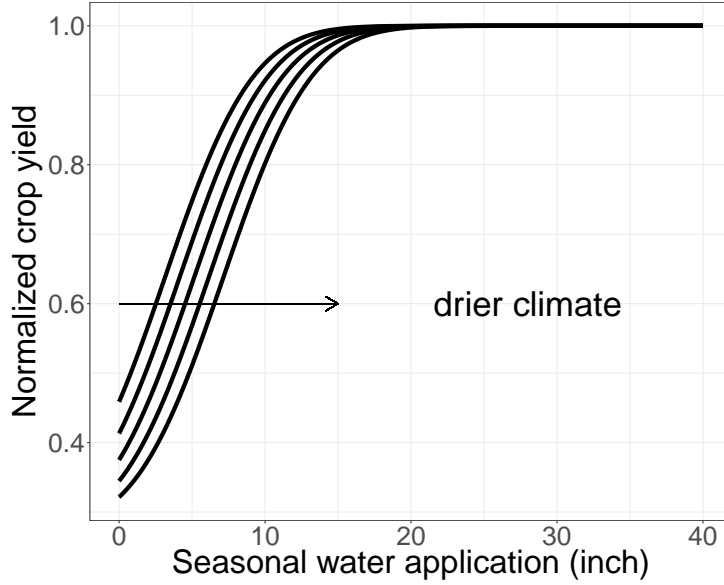

(a) $\Phi$ function

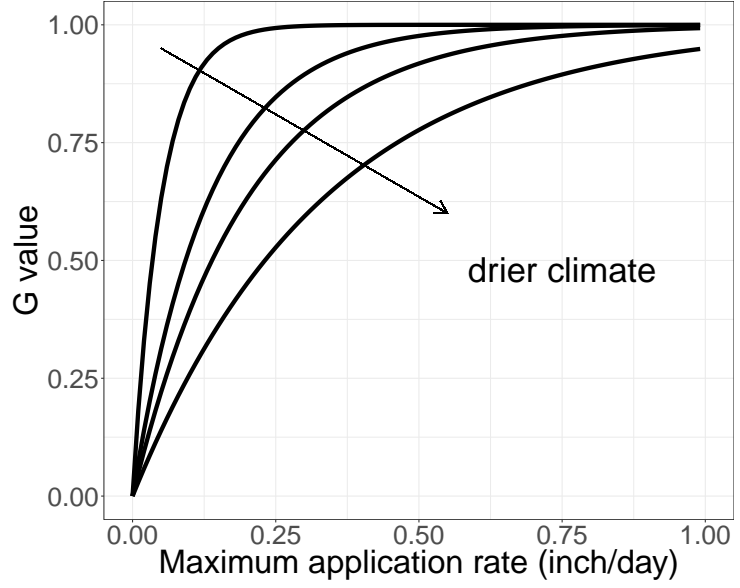

(b) G function

Figure 1: Elements of crop production function and the effect of changes in climatic conditions on crop yield. Panel a) shows $\Phi(u ; \epsilon, \theta)$ which is the effect of intra-seasonal water application on crop yield. Panel b) shows $G\left(\frac{X}{A}, \epsilon\right)$ which captures the effect of daily water availability on crop yield. 


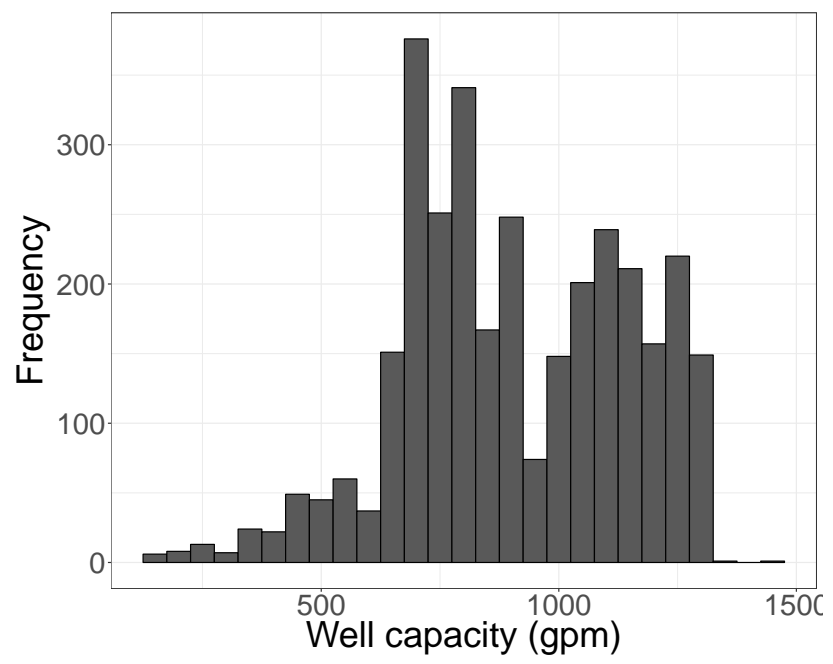

Figure 2: Histogram of well capacities in the Upper Republican Natural Resources District, Nebraska (source: Nebraska Department of Natural Resources) 


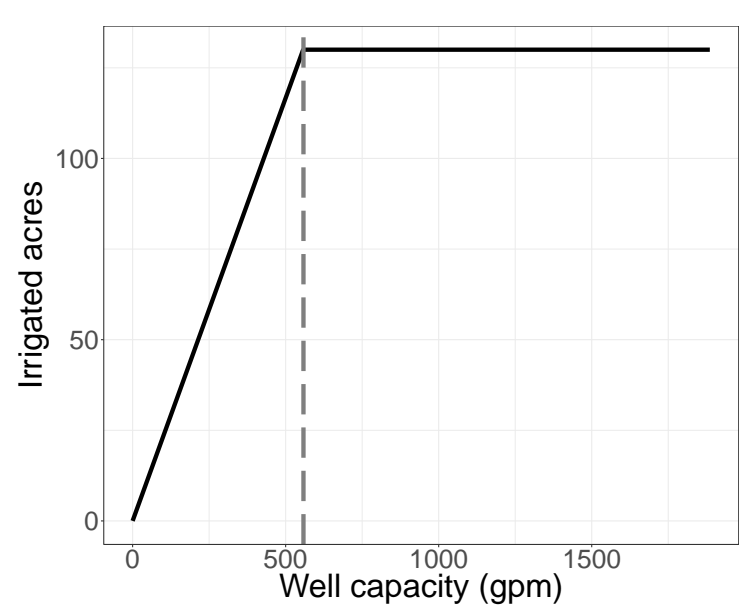

(a) Irrigated acres

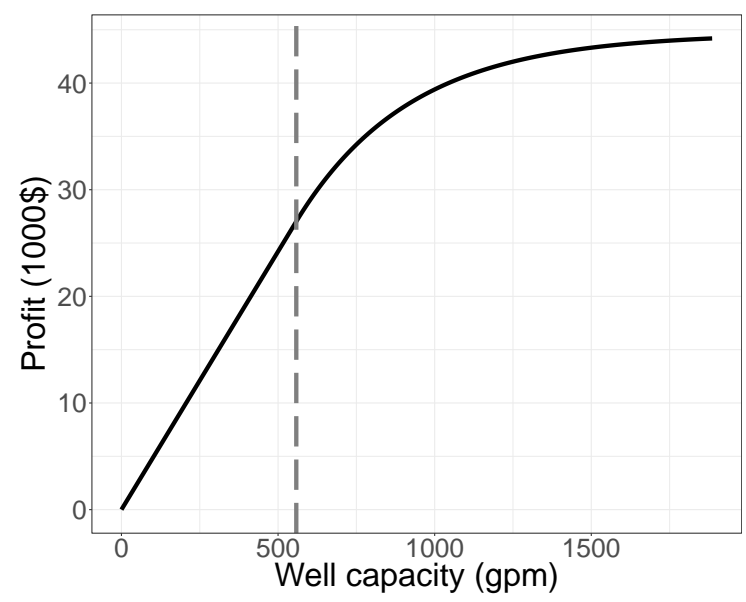

(c) Maximum profit

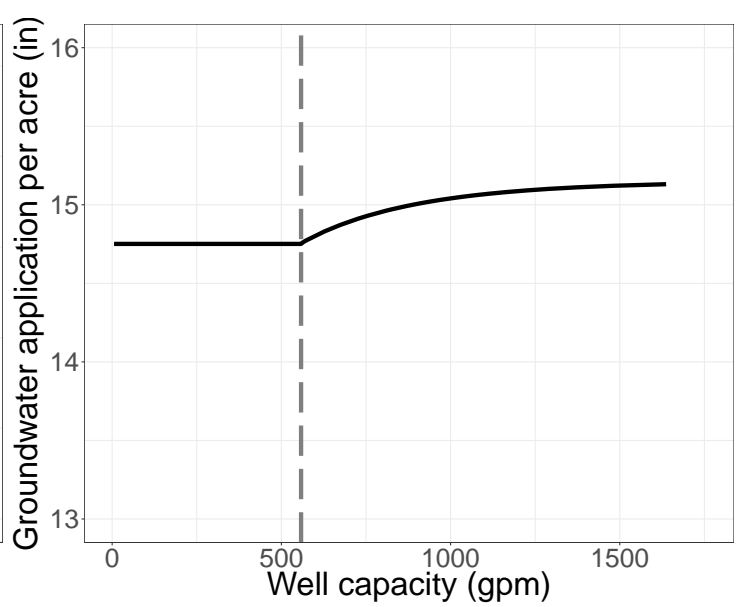

(b) Groundwater application per acre

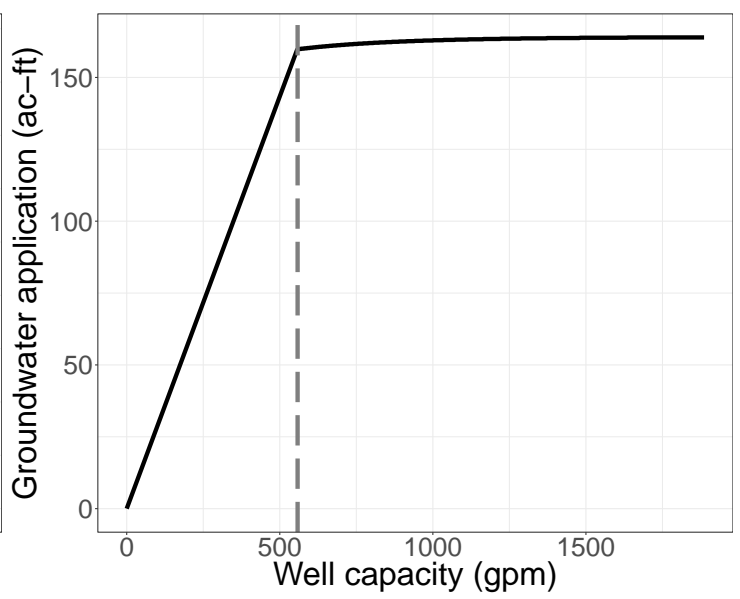

(d) Groundwater application

Figure 3: Profit-maximizing levels of a) irrigated acres b) groundwater application per acre, c) maximum profits, and d) groundwater application under different levels of instantaneous groundwater availability (well capacity). The dashed-line shows the switching point above which the decision is to adjust groundwater application per acre and below which the profitmaximizing decision is to adjust the number of irrigated acres as well capacity declines. 


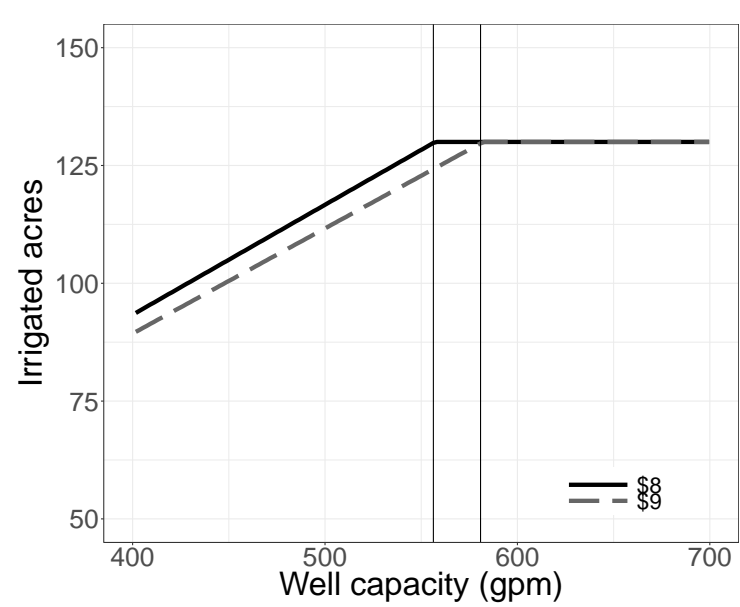

(a) Irrigated acres

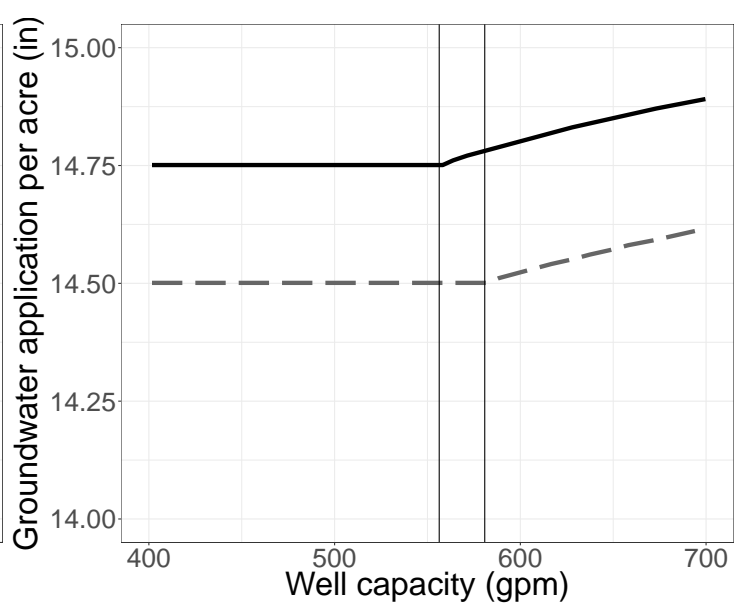

(b) Groundwater application per acre

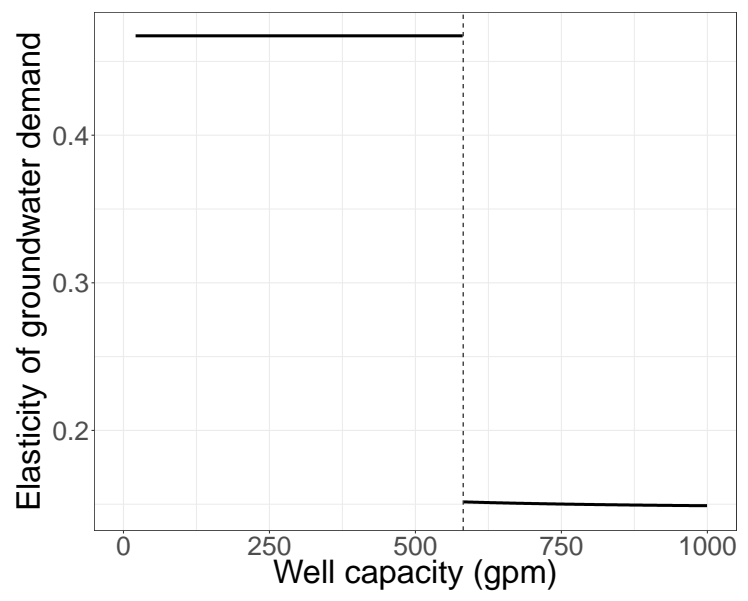

(c) Price Elasticity

Figure 4: Panels a) and b) show the number of irrigated acres and groundwater application per acre for a 130-acre field as a function of well capacity for two different pumping costs. As pumping cost increases, groundwater application per acre decreases, while the switching point shifts to the right. Panel c) shows the price elasticity of demand for groundwater for the range of well capacities. 


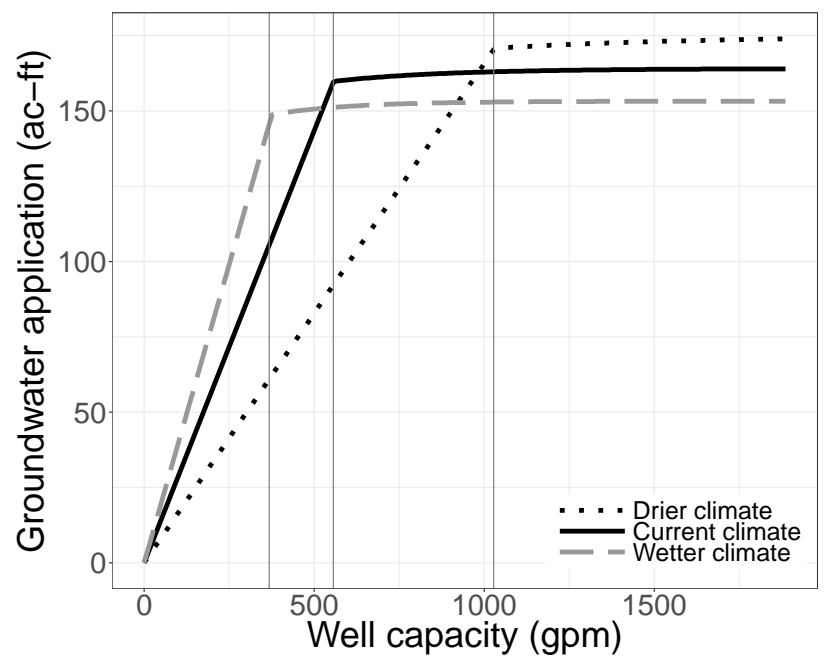

Figure 5: Effects of changes in climate, $\epsilon$, on groundwater application. As $\epsilon$ increases, the switching point shifts to the right. The figure shows a non-monotonic change in groundwater application from an increase in $\epsilon$. 


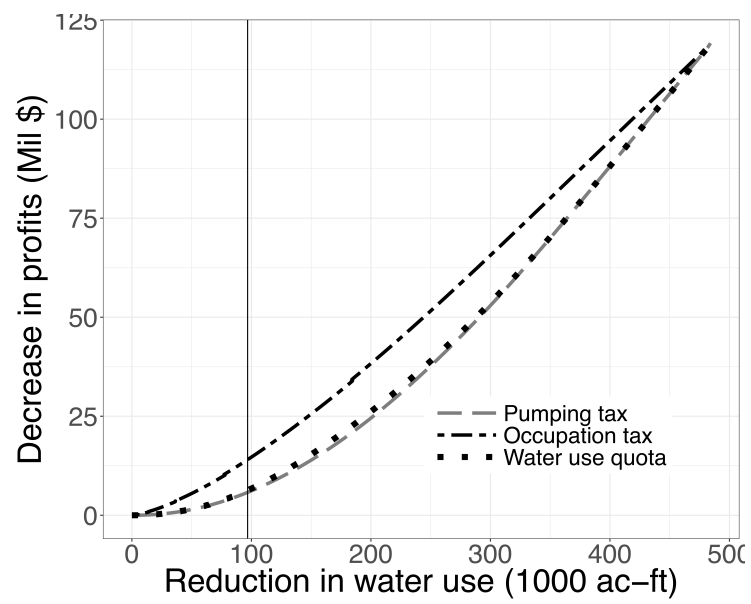

(a) Reduction in profit as a function of a reduction in water use in the study area
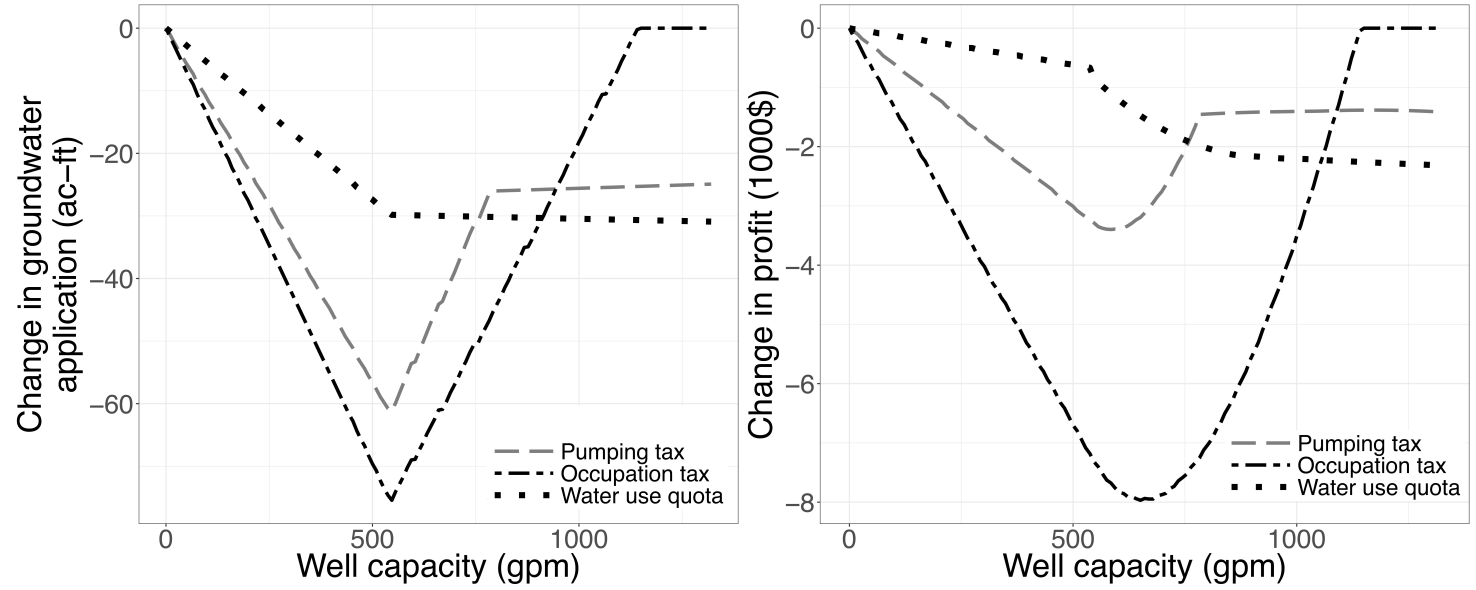

(b) Change in groundwater use across farm-(c) Change in profit across farmers with difers with different well capacities

ferent well capacities

Figure 6: Panel a) shows the loss of profit at the district level as a result of reducing water use for each policy. Total loss of profit is based on the distribution of well capacity within the district as shown in Figure 2. Panels b) and c) show changes in water use and profit for profit-maximizing farmers with different well capacities for each policy set to reduce total extraction in the District by 20\%. Each point in Panel a should be interpreted as a change in profit and change in water use for the entire district while each point in Panels b and c should be interpreted as change in water use and change in profit for each well respectively. 


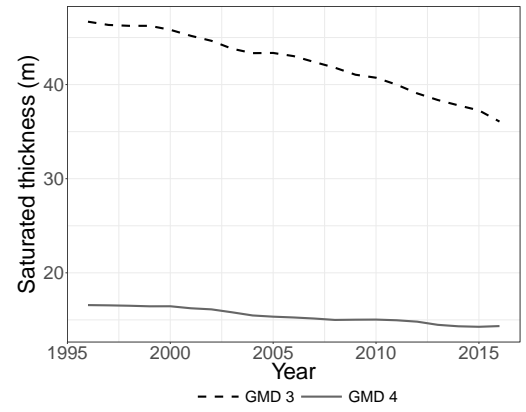

(a)

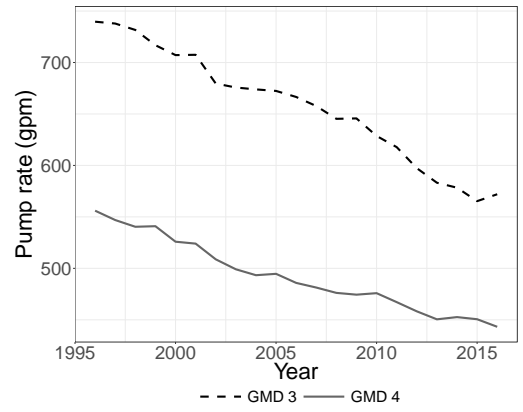

(b)

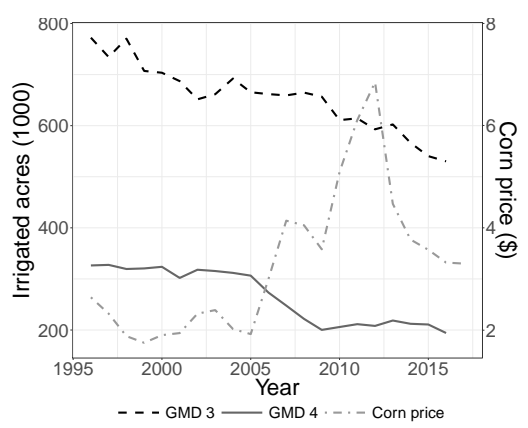

(c)

Figure 7: Figure shows changes in average saturated thickness of the aquifer (panel a), average pump rates (panel b) and total irrigated acres and annual corn prices (panel c) in two groundwater management districts (GMD) in Kansas. GMD 3, which is located in southwestern Kansas overall has greater saturated thickness than GMD 4, which is located in northwestern Kansas. However, more acres are also irrigated in GMD 3. Panel (b) shows changes in pump rates over the same period for the two districts. Panel (c) shows that irrigated acres decreased over time in both districts. This is despite that fact that crop prices have generally followed an increasing pattern over this time period. Panel (c) shows the pattern of corn prices that have increased from $\$ 2$ to around $\$ 7$ between 2005 and 2012. (Source of the saturated thickness data: (Haacker et al., 2016). Source of pump rate and irrigated acre data: Water Information Management and Analysis System by the Kansas Department of Agriculture, Division of Water Resources and Kansas Geological Survey. Corn price data were obtained from United States Department of Agriculture (USDA) National Agricultural Statistics Service (NASS)). 


\begin{tabular}{lllc}
\hline \hline Parameter & Desciption & Source & Value \\
\hline $\mathrm{P}$ & Price of corn per bushel $(\$)$ & UNL Crop Watch & 4 \\
$\Gamma()$. & Cost of pumping $(\$ / \mathrm{ac}-\mathrm{in})$ & (Martin et al., 2011) & 8 \\
$\mathrm{~K}$ & Fixed costs of production $(\$ / \mathrm{ac})$ & (Martin et al., 2007) & 400 \\
$y_{d}$ & Maximum dryland corn yield $(\mathrm{bu} / \mathrm{ac})$ & from AquaCrop output & 60 \\
$y_{m}+y_{d}$ & Maximum irrigated corn yield $(\mathrm{bu} / \mathrm{ac})$ & from AquaCrop output & 220 \\
$\alpha$ & (Parameter in G function) & fitted to AquaCrop output & 6.7 \\
$\epsilon$ & (Parameter in $\Phi$ function) & fitted to AquaCrop output & 5.1 \\
$\theta$ & (Parameter in $\Phi$ function) & fitted to AquaCrop output & 4.7 \\
\hline
\end{tabular}

${ }^{1}$ https://cropwatch. unl. edu/economics/corn.

Table 1: Parameter values used in the numerical analysis. 


\section{${ }^{1005}$ Appendices}

1026

1027

1028

1029

1030 1031

1032

1033

1034

1035

1036

1037

1038

\section{A Proofs}

Proposition 1. As $X \rightarrow \infty, A=1$ and $u=u_{\infty}(Y ; \theta, \epsilon)$.

Under the properties of the $G$ function, as $X \rightarrow \infty, G\left(\frac{X}{A}, \epsilon\right) \rightarrow 1$. Furthermore, when $X \rightarrow \infty$, the seasonal amount of groundwater available becomes unlimited, i.e., $h(X) \rightarrow \infty$ so that the total water availability constraint does not bind. The objective function then becomes:

$$
\operatorname{Max}_{A, u} \quad A\{\Phi(u ; \epsilon, \theta)-\Gamma(Y) u-K\}
$$

subject to

$$
\begin{aligned}
& A \leq 1 \\
& A, u \geq 0
\end{aligned}
$$

which is linear in the proportion of acres irrigated. At any positive $u$ where profits per acre are positive, $A=1$. Otherwise, when profits are negative, $A=u=0$. When $A=1$ objective function is concave in $\mathrm{u}$ over $[\epsilon, \infty)$, which means there exists a unique solution, $u_{\infty}$, for the first-order conditions:

$$
\Phi_{1}\left(u_{\infty} ; \epsilon, \theta\right)=\Gamma(Y) .
$$

Due to the concavity of the $\Phi$ function in the neighborhood of $u_{\infty}$, as marginal cost, $\Gamma(Y)$, increases, $u_{\infty}$ decreases. 


$$
\lambda_{2}=\left\{G\left(\frac{X}{A}, \epsilon\right)-\left(\frac{X}{A}\right) G_{1}\left(\frac{X}{A}, \epsilon\right)\right\} \Phi(u ; \epsilon, \theta)-\Gamma(Y) u-K
$$

and

$$
G\left(\frac{X}{A}, \epsilon\right) \Phi_{1}(u ; \epsilon, \theta)-\Gamma(Y)=0
$$

From equation 11, we can see that as $X \rightarrow \infty$, marginal revenues will become greater than the marginal costs and $\lambda_{2}$ is positive, which means $A=1$ is binding and with large enough $X_{s}, \lambda_{2}$ will still be greater than zero. Thus, assuming $A=1$ and fixed ${ }^{23}$ taking the partial derivative of Equation 12 with respect to $X$, we can see that as well capacity decreases, optimal water application rate decreases at the rate:

\footnotetext{
${ }^{23}$ Equation 13 follows only from Equation 11 and by keeping $A=1$. By keeping $A=1$ fixed, we do not need to take the total derivative of the KKT conditions.
} 


$$
\frac{\partial u}{\partial X}=-\frac{\frac{1}{A} G_{1}\left(\frac{X}{A}, \epsilon\right) \Phi_{1}(u ; \epsilon, \theta)}{G\left(\frac{X}{A}, \epsilon\right) \Phi_{11}(u ; \epsilon, \theta)}>0
$$

along the concave region of the production function. This is because a change in well capacity affects the marginal profit of adding an inch, i.e., as well capacity decreases the marginal benefit of adding an inch decreases and a producer will adjust intensive margin applications.

To see how a decrease in well capacity affects shadow value of adding an acre, we take the derivative of equation 11 with respect to $X$ :

$$
\frac{\partial \lambda_{2}}{\partial X}=-\left(\frac{X}{A}\right) G_{11}\left(\frac{X}{A}, \epsilon\right) \Phi(u ; \epsilon, \theta)+\left\{G\left(\frac{X}{A}, \epsilon\right)-\left(\frac{X}{A}\right) G_{1}\left(\frac{X}{A}, \epsilon\right)\right\} \Phi_{1}(u ; \epsilon, \theta) \frac{\partial u}{\partial X}-\Gamma(Y) \frac{\partial u}{\partial X}
$$

where the first term is the effect of a change in well capacity on shadow value of adding an acre keeping the amount of water applied fixed, i.e., the effect only through a change in productivity due to instantaneous groundwater availability. The second term is the effect of a change in water application from a marginal change in well capacity (intensive margin adjustment), and the last term is the change in per acre cost of applying water. Since $\lambda_{2}>0$ and $A=1$, we impose that $\frac{\partial A}{\partial X}=0$.

We can see that as $X \rightarrow \infty, u \rightarrow u_{\infty}^{*}$ which is the unconstrained amount of seasonal application per acre and is a constant. Thus, $\frac{\partial u}{\partial X} \rightarrow 0$ and $\frac{\partial \lambda_{2}}{\partial X}>0$. All three terms in equation 14 are positive which means that as well capacity decreases both marginal benefit of adding an acre and marginal cost of adding an acre decrease. However, we know that eventually marginal benefit decreases at a much faster rate due to the concavity of production function while marginal cost decreases at a fixed rate. Thus, there exists a well capacity, $X_{s}$, where $A=1$ does not bind anymore. This well capacity is the intersection of the two 
hyperplanes with $\lambda_{2}=0$ and $A=1$. We call this point the switching point, and it is defined by the following equations:

$$
\left\{G\left(X_{s}, \epsilon\right)-\left(X_{s}\right) G_{1}\left(X_{s}, \epsilon\right)\right\} \Phi(u ; \epsilon, \theta)-\Gamma(Y) u-K=0
$$

and

$$
G\left(X_{s}, \epsilon\right) \Phi_{1}(u ; \epsilon, \theta)-\Gamma(Y)=0 .
$$

Equation 16 provides a unique $u^{*}$ for any $X$ at $A=1$. Replacing $u^{*}$ into equation 15 we get a unique $X_{s}(Y, \epsilon ; \theta)$.

Next, in order to see the change in optimal irrigation decision for well capacities below $X_{s}$, we take the derivative of Equations $7 \mathrm{a}$ and $7 \mathrm{~b}$ with respect to $X$ under the condition of $\lambda_{1}=\lambda_{2}=0$. However, we first note that in Equation $7 \mathrm{~b}$ for any $A>0$ :

$$
G\left(\frac{X}{A}, \epsilon\right) \Phi_{1}(u ; \epsilon, \theta)-\Gamma(Y)=0
$$

Taking the derivative of the above equation with respect to $X$, we get:

$$
\left(\frac{A-A^{\prime} X}{A^{2}}\right)\left\langle G_{1}\left(\frac{X}{A}, \epsilon\right) \Phi_{1}(u ; \epsilon, \theta)\right\rangle+\left\langle G\left(\frac{X}{A}, \epsilon\right) \Phi_{11}(u ; \epsilon, \theta)\right\rangle u^{\prime}=0 .
$$

where $u^{\prime}=\frac{\partial u}{\partial X}$ and $A^{\prime}=\frac{\partial A}{\partial X}$. Taking the derivative of Equation 7a with respect to $X$ we get:

$$
\left(\frac{A-A^{\prime} X}{A^{2}}\right)\left\langle G_{11}\left(\frac{X}{A}, \epsilon\right) \Phi(u ; \epsilon, \theta)\right\rangle-\left\langle G_{1}\left(\frac{X}{A}, \epsilon\right) \Phi_{1}(u ; \epsilon, \theta)\right\rangle u^{\prime}=0 .
$$


The two equations above, i.e., Equations 18 and 19, show two terms: one multiplied by $\left(\frac{A-A^{\prime} X}{A^{2}}\right)$ and one multiplied by $u^{\prime}$. We can simplify Equation 18 and write it as:

$$
\left(\frac{A-A^{\prime} X}{A^{2}}\right)\langle+\rangle+\langle-\rangle u^{\prime}=0
$$

where $\langle+\rangle$ shows that the sign of the terms is positive and $\langle-\rangle$ shows that the sign of the terms is negative. We can also simplify Equation 19 and write it as:

$$
\left(\frac{A-A^{\prime} X}{A^{2}}\right)\langle-\rangle-\langle+\rangle u^{\prime}=0
$$

if $u^{\prime}>0$, then from Equation 20, $\left(\frac{A-A^{\prime} X}{A^{2}}\right)$ needs to be greater than zero. However, this does not satisfy Equation 21. On the other hand if if $u^{\prime}<0$, then from Equation $20,\left(\frac{A-A^{\prime} X}{A^{2}}\right)$ needs to be less than zero. Again, this does not satisfy Equation 21. As a result, the only condition under which both equations are satisfied is when $\left(\frac{A-A^{\prime} X}{A^{2}}\right)=0$ and $u^{\prime}=0$, i.e., for well capacities below the switching point, intensive margin application does not change as a result of decreasing well capacity. Furthermore, from $\left(\frac{A-A^{\prime} X}{A^{2}}\right)=0$ we get:

$$
\frac{\partial A}{\partial X}=\frac{A}{X} \rightarrow E_{X A}=\frac{\partial A / A}{\partial X / X}=1
$$

Where $E_{X A}$ can be defined as the elasticity of irrigated acres as well capacity changes by 1 percent. This elasticity is fixed for well capacities below $X_{s}$ suggesting that a $1 \%$ change in well capacity translates into a $1 \%$ change in irrigated acres. 
and

\section{B Comparative Statics}

Comparative Statics 1. Effects of an increase in cost of pumping. To see the effect of an increase in the cost of pumping on irrigation decisions, we divide the problem into two parts: well capacities above the switching point and well capacities below the switching point. For well capacities above the switching point, $A=1$ and $\lambda_{2}>0$. Under these conditions, we study the changes in irrigation intensity, $u$, and the shadow value of adding an acre, $\lambda_{2}$. Given that the switching point is a kink and non-differentiable, it is not possible to study its shift as a result of a change in the cost of pumping. Studying the changes in $\lambda_{2}$ due to a change in cost of pumping in this segment of the domain of well capacity allows us to analyze the change in switching point. For well capacities below the switching point $A<1$ and $\lambda_{1}=\lambda_{2}=0$. When $A<1$, we consider the full set of first-order conditions for $A$ and $u$.

In order to study the effect of an increase in the cost of pumping on per acre application rate and shadow value of adding an acre for well capacities above the switching point, we take the derivative of Equations 11 and 12 with respect to $\Gamma(Y)$ :

$$
\begin{array}{r}
\frac{\partial}{\partial \Gamma(Y)}\left\{\lambda_{2}-\left\{G\left(\frac{X}{A}, \epsilon\right)-\left(\frac{X}{A}\right) G_{1}\left(\frac{X}{A}, \epsilon\right)\right\} \Phi(u ; \epsilon, \theta)+\Gamma(Y) u+K\right\}= \\
\frac{\partial \lambda_{2}}{\partial \Gamma(Y)}-\left\{G\left(\frac{X}{A}, \epsilon\right)-\left(\frac{X}{A}\right) G_{1}\left(\frac{X}{A}, \epsilon\right)\right\} \Phi_{1}(u ; \epsilon, \theta) \frac{\partial u}{\partial \Gamma(Y)}+u+\Gamma(Y) \frac{\partial u}{\partial \Gamma(Y)}= \\
\frac{\partial \lambda_{2}}{\partial \Gamma(Y)}-\left\{\left\{G\left(\frac{X}{A}, \epsilon\right)-\left(\frac{X}{A}\right) G_{1}\left(\frac{X}{A}, \epsilon\right)\right\} \Phi_{1}(u ; \epsilon, \theta)-\Gamma(Y)\right\} \frac{\partial u}{\partial \Gamma(Y)}+u=0 \longrightarrow \\
\frac{\partial \lambda_{2}}{\partial \Gamma(Y)}-\left\{\left\{G\left(\frac{X}{A}, \epsilon\right)-\left(\frac{X}{A}\right) G_{1}\left(\frac{X}{A}, \epsilon\right)\right\} \Phi_{1}(u ; \epsilon, \theta)-\Gamma(Y)\right\} \frac{\partial u}{\partial \Gamma(Y)}=-u
\end{array}
$$




$$
\begin{array}{r}
\frac{\partial}{\partial \Gamma(Y)}\left\{G\left(\frac{X}{A}, \epsilon\right) \Phi_{1}(u ; \epsilon, \theta)-\Gamma(Y)\right\}= \\
G\left(\frac{X}{A}, \epsilon\right) \Phi_{11}(u ; \epsilon, \theta) \frac{\partial u}{\partial \Gamma(Y)}-1=0 \longrightarrow \\
G\left(\frac{X}{A}, \epsilon\right) \Phi_{11}(u ; \epsilon, \theta) \frac{\partial u}{\partial \Gamma(Y)}=1
\end{array}
$$

${ }_{1117}$ We can then write the system as:

$$
\begin{aligned}
& {\left[\begin{array}{cc}
-\left\{G\left(\frac{X}{A}, \epsilon\right)-\left(\frac{X}{A}\right) G_{1}\left(\frac{X}{A}, \epsilon\right)\right\} \Phi_{1}(u ; \epsilon, \theta)+\Gamma(Y) & 1 \\
G\left(\frac{X}{A}, \epsilon\right) \Phi_{11}(u ; \epsilon, \theta) & 0
\end{array}\right]\left[\begin{array}{c}
\frac{\partial u}{\partial \Gamma} \\
\frac{\partial \lambda_{2}}{\partial \Gamma}
\end{array}\right]} \\
& =\left[\begin{array}{c}
-u \\
1
\end{array}\right] \\
& \frac{\partial u}{\partial \Gamma(Y)}=-u \times 0-1 \times 1<0
\end{aligned}
$$

1118

and similarly for $\frac{\partial \lambda_{2}}{\partial \Gamma(Y)}$, we have:

$$
\begin{array}{r}
-\left\{G\left(\frac{X}{A}, \epsilon\right)-\left(\frac{X}{A}\right) G_{1}\left(\frac{X}{A}, \epsilon\right)\right\} \Phi_{1}(u ; \epsilon, \theta)+\Gamma(Y)+u G\left(\frac{X}{A}, \epsilon\right) \Phi_{11}(u ; \epsilon, \theta)= \\
\left(\frac{X}{A}\right) G_{1}\left(\frac{X}{A}, \epsilon\right) \Phi_{1}(u ; \epsilon, \theta)+u G\left(\frac{X}{A}, \epsilon\right) \Phi_{11}(u ; \epsilon, \theta)=
\end{array}
$$

1119 The sign of the term can be determined by comparing $G\left(\frac{X}{A}, \epsilon\right)$ with $\left(\frac{X}{A}\right) G_{1}\left(\frac{X}{A}, \epsilon\right)$ and comparing $\Phi_{11}(u ; \epsilon, \theta) u$ with $\Phi_{1}(u ; \epsilon, \theta)$. We notice that since $G$ is concave in its first argument, $G\left(\frac{X}{A}, \epsilon\right)>\left(\frac{X}{A}\right) G_{1}\left(\frac{X}{A}, \epsilon\right)$ and since the concave region of $\Phi$ is convex for a CDF function, $\Phi_{11}(u ; \epsilon, \theta) u>\Phi_{1}(u ; \epsilon, \theta)$. As a result, $\frac{\partial \lambda_{2}}{\partial \Gamma}<0$, i.e. as pumping cost increases, shadow value 
1123

1124

The matrix form of the equations above can be written as: shifts to the right.

And the total derivative of Equation 7b becomes:

of adding an acre decreases. A decrease in the shadow value means that the switching point

In order to see the effects of a marginal change in pumping cost on intensive and extensive margins of groundwater application below the switching point, i.e., $X<X_{s}$, we take the derivative of the Equations $7 \mathrm{a}$ and $7 \mathrm{~b}$ with respect to pumping cost, $\Gamma(Y)$. The total derivative of Equation 7a becomes (for notational simplicity we use $\Gamma$ in lieu of $\Gamma(Y)$ ):

$$
\begin{array}{r}
\left\{-\left(\frac{X}{A}\right)\left(\frac{-X \frac{\partial A}{\partial \Gamma}}{A^{2}}\right) G_{11}\left(\frac{X}{A}, \epsilon\right)\right\} \Phi(u ; \epsilon, \theta)+ \\
\left\{G\left(\frac{X}{A}, \epsilon\right)-\left(\frac{X}{A}\right) G_{1}\left(\frac{X}{A}, \epsilon\right)\right\} \Phi_{1}(u ; \epsilon, \theta) \frac{\partial u}{\partial \Gamma}-u-\Gamma \frac{\partial u}{\partial \Gamma}=0 \longrightarrow \\
\left\{\left(\frac{X^{2}}{A^{3}}\right) G_{11}\left(\frac{X}{A}, \epsilon\right) \Phi(u ; \epsilon, \theta)\right\} \frac{\partial A}{\partial \Gamma}+ \\
\left\{\left\{G\left(\frac{X}{A}, \epsilon\right)-\left(\frac{X}{A}\right) G_{1}\left(\frac{X}{A}, \epsilon\right)\right\} \Phi_{1}(u ; \epsilon, \theta)-\Gamma\right\} \frac{\partial u}{\partial \Gamma}-u=0
\end{array}
$$

$$
\begin{aligned}
& \frac{\partial A}{\partial \Gamma}\left\{G\left(\frac{X}{A}, \epsilon\right) \Phi_{1}(u ; \epsilon, \theta)-\Gamma\right\}+ \\
& A\left\{\left(\frac{-X \frac{\partial A}{\partial \Gamma}}{A^{2}}\right) G_{1}\left(\frac{X}{A}, \epsilon\right) \Phi_{1}(u ; \epsilon, \theta)+G\left(\frac{X}{A}, \epsilon\right) \Phi_{11}(u ; \epsilon, \theta) \frac{\partial u}{\partial \Gamma}-1\right\}=0 \longrightarrow \\
& \left\{\left\{G\left(\frac{X}{A}, \epsilon\right)-\left(\frac{X}{A}\right) G_{1}\left(\frac{X}{A}, \epsilon\right)\right\} \Phi_{1}(u ; \epsilon, \theta)-\Gamma\right\} \frac{\partial A}{\partial \Gamma}+ \\
& \left\{A G\left(\frac{X}{A}, \epsilon\right) \Phi_{11}(u ; \epsilon, \theta)\right\} \frac{\partial u}{\partial \Gamma}-A=0
\end{aligned}
$$




$$
\begin{aligned}
& {\left[\begin{array}{cc}
\left(\frac{X^{2}}{A^{3}}\right) G_{11}\left(\frac{X}{A}, \epsilon\right) \Phi(u ; \epsilon, \theta) & \left\{G\left(\frac{X}{A}, \epsilon\right)-\left(\frac{X}{A}\right) G_{1}\left(\frac{X}{A}, \epsilon\right)\right\} \Phi_{1}(u ; \epsilon, \theta)-\Gamma \\
\left\{G\left(\frac{X}{A}, \epsilon\right)-\left(\frac{X}{A}\right) G_{1}\left(\frac{X}{A}, \epsilon\right)\right\} \Phi_{1}(u ; \epsilon, \theta)-\Gamma & A G\left(\frac{X}{A}, \epsilon\right) \Phi_{11}(u ; \epsilon, \theta)
\end{array}\right]\left[\begin{array}{c}
\frac{\partial A}{\partial \Gamma} \\
\frac{\partial u}{\partial \Gamma}
\end{array}\right]} \\
& =\left[\begin{array}{l}
u \\
A
\end{array}\right]
\end{aligned}
$$

We can then get the change in $A$ and $u$ as a result of a change in $\Gamma$ through Kramer's rule:

$$
\frac{\partial A}{\partial \Gamma}=\frac{\left|\begin{array}{cc}
u & \left\{G\left(\frac{X}{A}, \epsilon\right)-\left(\frac{X}{A}\right) G_{1}\left(\frac{X}{A}, \epsilon\right)\right\} \Phi_{1}(u ; \epsilon, \theta)-\Gamma \mid \\
A & A G\left(\frac{X}{A}, \epsilon\right) \Phi_{11}(u ; \epsilon, \theta)
\end{array}\right|}{\mid\left(\frac{X^{2}}{A^{3}}\right) G_{11}\left(\frac{X}{A}, \epsilon\right) \Phi(u ; \epsilon, \theta)}\left\{\begin{array}{c}
\left\{\left(\frac{X}{A}, \epsilon\right)-\left(\frac{X}{A}\right) G_{1}\left(\frac{X}{A}, \epsilon\right)\right\} \Phi_{1}(u ; \epsilon, \theta)-\Gamma \mid \\
\left\{G\left(\frac{X}{A}, \epsilon\right)-\left(\frac{X}{A}\right) G_{1}\left(\frac{X}{A}, \epsilon\right)\right\} \Phi_{1}(u ; \epsilon, \theta)-\Gamma
\end{array}\right.
$$

The denominator is the Hessian of the second order conditions and as a result should be positive. We assume that this condition holds. Consequently, the sign of the numerator determines the sign of $\frac{\partial A}{\partial \Gamma}$. The determinant in the numerator can be written as:

$$
A u G\left(\frac{X}{A}, \epsilon\right) \Phi_{11}(u ; \epsilon, \theta)-A\left\{\left\{G\left(\frac{X}{A}, \epsilon\right)-\left(\frac{X}{A}\right) G_{1}\left(\frac{X}{A}, \epsilon\right)\right\} \Phi_{1}(u ; \epsilon, \theta)-\Gamma\right\}
$$

Both of the terms in the equation above are negative. To see why the second equation is negative, notice that from the first-order conditions $G\left(\frac{X}{A}, \epsilon\right) \Phi_{1}(u ; \epsilon, \theta)=\Gamma(Y)$, i.e., the second term is equal to $-\left(\frac{X}{A}\right) G_{1}\left(\frac{X}{A}, \epsilon\right)<0$. Thus, the sign seems undetermined. However, we can combine the two terms and get: 


$$
\begin{array}{r}
A\left\{u G\left(\frac{X}{A}, \epsilon\right) \Phi_{11}(u ; \epsilon, \theta)-\left\{G\left(\frac{X}{A}, \epsilon\right)-\left(\frac{X}{A}\right) G_{1}\left(\frac{X}{A}, \epsilon\right)\right\} \Phi_{1}(u ; \epsilon, \theta)-\Gamma\right\}= \\
A\left\{G\left(\frac{X}{A}, \epsilon\right) \Phi_{11}(u ; \epsilon, \theta) u+\left(\frac{X}{A}\right) G_{1}\left(\frac{X}{A}, \epsilon\right) \Phi_{1}(u ; \epsilon, \theta)\right\}
\end{array}
$$

1140

1141 1142 1143 1144

The sign of the term can be determined by comparing $G\left(\frac{X}{A}, \epsilon\right)$ with $\left(\frac{X}{A}\right) G_{1}\left(\frac{X}{A}, \epsilon\right)$ and comparing $\Phi_{11}(u ; \epsilon, \theta) u$ with $\Phi_{1}(u ; \epsilon, \theta)$. We notice that since $G$ is concave in its first argument, $G\left(\frac{X}{A}, \epsilon\right)>\left(\frac{X}{A}\right) G_{1}\left(\frac{X}{A}, \epsilon\right)$ and since the concave region of $\Phi$ is convex for a CDF function, $\Phi_{11}(u ; \epsilon, \theta) u>\Phi_{1}(u ; \epsilon, \theta)$. As a result, $\frac{\partial A}{\partial \Gamma}<0$.

Similarly, we can find the sign of $\frac{\partial u}{\partial \Gamma}$ :

$$
\frac{\partial u}{\partial \Gamma}=\frac{\left|\left\{G\left(\frac{X}{A}, \epsilon\right)-\left(\frac{X}{A}\right) G_{1}\left(\frac{X}{A}, \epsilon\right)\right\} \Phi_{1}(u ; \epsilon, \theta)-\Gamma \quad A\right|}{\left|\begin{array}{cc}
\left(\frac{X^{2}}{A^{3}}\right) G_{11}\left(\frac{X}{A}, \epsilon\right) \Phi(u ; \epsilon, \theta) & u \mid \\
\left(\frac{X^{2}}{A^{3}}\right) G_{11}\left(\frac{X}{A}, \epsilon\right) \Phi(u ; \epsilon, \theta) & \left\{G\left(\frac{X}{A}, \epsilon\right)-\left(\frac{X}{A}\right) G_{1}\left(\frac{X}{A}, \epsilon\right)\right\} \Phi_{1}(u ; \epsilon, \theta)-\Gamma \mid
\end{array}\right|}
$$

the numerator becomes:

$$
\left(\frac{X}{A}\right) G_{11}\left(\frac{X}{A}, \epsilon\right) \Phi(u ; \epsilon, \theta)+G_{1}\left(\frac{X}{A}, \epsilon\right) \Phi_{1}(u ; \epsilon, \theta) u
$$

Given that $\Phi$ is concave is the region of $u^{*}, \Phi(u ; \epsilon, \theta)>\Phi^{\prime}(u ; \epsilon, \theta) u$. As long as $G_{1}\left(\frac{X}{A}, \epsilon\right)$ is not concave, $\frac{\partial u}{\partial \Gamma}<0$. E.g $G_{1}\left(\frac{X}{A}, \epsilon\right)$ is convex if the marginal effects become severe at an increasing rate as well capacity declines. This is the case for our specific functional form selected for $G$. 
Comparative Statics 2. Effects of a change in average climate conditions. We divide the effects of average climatic conditions on intensive and extensive margins of application and the switching point in two parts. We first study the effects of a drier climate on intensive margin application for well capacities greater than the switching point and on the switching point. Then, we study the effect of a drier climate on intensive and extensive margins of application for well capacities below the switching point.

To see the effect of a drier climate on the profit-maximizing quantity of water applied per acre for well capacities greater than the switching point, we take the derivative of 12 with respect to $\epsilon$ :

$$
\frac{\partial u}{\partial \epsilon}=-\frac{G(X, \epsilon) \frac{\partial \Phi_{1}(u ; \epsilon, \theta)}{\partial \epsilon}+\frac{\partial G(X, \epsilon)}{\partial \epsilon} \Phi_{1}(u ; \epsilon, \theta)}{G(X, \epsilon) \Phi_{11}(u ; \epsilon, \theta)}
$$

where the first term in the numerator shows the effect of drier climate on marginal benefit of adding a unit of water by increasing seasonal water demand, while the second term shows the effect of drier climate on marginal benefit of adding a unit of water through daily water availability. The first term in the numerator of equation 27 is positive showing that as climate gets drier, marginal benefit of adding a unit of water over the season increases. The second term in equation 27 is negative suggesting that as the climate gets drier, the marginal benefit of adding a unit of water can decrease. The intuition is that with limited well capacity a farmer is not able to meet the demand during the critical stages of crop growth when water availability matters in a dry year. As a result, applying more water after the peak demand, when the crop yield has already suffered, has less effect on yield than when the demand is fully met. Obviously, we do not expect this effect to be significant for high well capacities. We expect water application, $u$, to be dominated by seasonal water demand. This is obvious from $\frac{\partial G(X, \epsilon)}{\partial \epsilon}$, which approaches zero for large well capacities. However, as well capacity decreases, $\frac{\partial G(X, \epsilon)}{\partial \epsilon}$ increases (because the cross partial derivative, $\frac{\partial G^{2}(X, \epsilon)}{\partial \frac{X}{A} \partial \epsilon}$, is negative) and the numerator becomes negative. We will see the implication of this observation when 
we consider the effect of drier climatic conditions for well capacities below the switching point.

In order to see the effect of a drier climate on the switching point, we look at the effect of a change in $\epsilon$ on the shadow value of adding an acre, equation 11, when $A=1$ :

$$
\begin{array}{r}
\frac{\partial \lambda_{2}}{\partial \epsilon}=\left\{\frac{\partial G(X, \epsilon)}{\partial \epsilon}-X \frac{\partial G_{1}(X, \epsilon)}{\partial \epsilon}\right\} \Phi(u ; \epsilon, \theta)+ \\
\left\{\left\{G(X, \epsilon)-X G_{1}(X, \epsilon)\right\} \Phi_{1}(u ; \epsilon, \theta)-\Gamma(Y)\right\} \frac{\partial u}{\partial \epsilon}+ \\
\left\{G(X, \epsilon)-X G_{1}(X, \epsilon)\right\} \frac{\partial \Phi(u ; \epsilon, \theta)}{\partial \epsilon}
\end{array}
$$

The first term is the effect of a drier climate on the marginal benefit of adding an acre through daily water availability, and it is negative for two reasons. First, as the climate gets drier, keeping the amount of water applied and the maximum daily application rate fixed, crop yield will decrease. Second, adding an acre results in lower maximum daily application rate per acre. As the climate gets drier, the effect of lower maximum daily water available on crop yield becomes more significant. These two effects together mean that as the climate gets drier, shadow value of adding an acre decreases due to inability to meet daily crop water demand. The second term in equation 28 is the effect of seasonal water demand in a drier on shadow value of adding an acre. As we saw above, it is negative. Finally, the last term shows the effect of a drier climate keeping seasonal application and maximum daily application rate fixed. Keeping everything fixed, in a drier climate, the shadow value of adding an acre is lower and the last term is negative. All three terms are negative, suggesting that shadow value of adding an acre decreases as the climate gets drier. Thus, under a drier climate, the switching point shifts to the right.

To see the effect of a change in climatic conditions on intensive and extensive margins of 
groundwater application, we first take the total derivative of Equation 12 with respect to $\epsilon$ :

In order to see the effects of a marginal change in climatic conditions on intensive and extensive margins of groundwater application below the switching point, i.e., $X<X_{s}$, we take the derivative of the Equations $7 \mathrm{a}$ and $7 \mathrm{~b}$ with respect to $\epsilon$. The total derivative of Equation 7a becomes:

$$
\begin{array}{r}
\left\{-\left(\frac{X}{A}\right)\left(\frac{-X \frac{\partial A}{\partial \epsilon}}{A^{2}}\right) G_{11}\left(\frac{X}{A}, \epsilon\right)\right\} \Phi(u ; \epsilon, \theta)+ \\
\left\{G\left(\frac{X}{A}, \epsilon\right)-\left(\frac{X}{A}\right) G_{1}\left(\frac{X}{A}, \epsilon\right)\right\} \Phi_{1}(u ; \epsilon, \theta) \frac{\partial u}{\partial \epsilon}-\Gamma \frac{\partial u}{\partial \epsilon}+ \\
\left\{G_{2}\left(\frac{X}{A}, \epsilon\right)-\left(\frac{X}{A}\right) G_{12}\left(\frac{X}{A}, \epsilon\right)\right\} \Phi(u ; \epsilon, \theta)+\left\{G\left(\frac{X}{A}, \epsilon\right)-\left(\frac{X}{A}\right) G_{1}\left(\frac{X}{A}, \epsilon\right)\right\} \Phi_{\epsilon}(u ; \epsilon, \theta)=0 \longrightarrow \\
\left\{\left(\frac{X^{2}}{A^{3}}\right) G_{11}\left(\frac{X}{A}, \epsilon\right) \Phi(u ; \epsilon, \theta)\right\} \frac{\partial A}{\partial \epsilon}+ \\
\left\{\left\{G\left(\frac{X}{A}, \epsilon\right)-\left(\frac{X}{A}\right) G_{1}\left(\frac{X}{A}, \epsilon\right)\right\} \Phi_{1}(u ; \epsilon, \theta)-\Gamma\right\} \frac{\partial u}{\partial \epsilon}= \\
-\left\{G_{2}\left(\frac{X}{A}, \epsilon\right)-\left(\frac{X}{A}\right) G_{12}\left(\frac{X}{A}, \epsilon\right)\right\} \Phi(u ; \epsilon, \theta)-\left\{G\left(\frac{X}{A}, \epsilon\right)-\left(\frac{X}{A}\right) G_{1}\left(\frac{X}{A}, \epsilon\right)\right\} \Phi_{\epsilon}(u ; \epsilon, \theta)
\end{array}
$$

And the total derivative of Equation $7 \mathrm{~b}$ becomes: 


$$
\begin{aligned}
& \frac{\partial A}{\partial \epsilon}\left\{G\left(\frac{X}{A}, \epsilon\right) \Phi_{1}(u ; \epsilon, \theta)-\Gamma\right\}+ \\
& A\left\{\left(\frac{-X \frac{\partial A}{\partial \epsilon}}{A^{2}}\right) G_{1}\left(\frac{X}{A}, \epsilon\right) \Phi_{1}(u ; \epsilon, \theta)+G\left(\frac{X}{A}, \epsilon\right) \Phi_{11}(u ; \epsilon, \theta) \frac{\partial u}{\partial \epsilon}\right\}+ \\
& A\left\{G_{2}\left(\frac{X}{A}, \epsilon\right) \Phi_{1}(u ; \epsilon, \theta)+G\left(\frac{X}{A}, \epsilon\right) \Phi_{12}(u ; \epsilon, \theta)\right\}=0 \longrightarrow \\
& \left\{\left\{G\left(\frac{X}{A}, \epsilon\right)-\left(\frac{X}{A}\right) G_{1}\left(\frac{X}{A}, \epsilon\right)\right\} \Phi_{1}(u ; \epsilon, \theta)-\Gamma\right\} \frac{\partial A}{\partial \epsilon}+ \\
& \left\{A G\left(\frac{X}{A}, \epsilon\right) \Phi_{11}(u ; \epsilon, \theta)\right\} \frac{\partial u}{\partial \epsilon}= \\
& -A\left\{G_{2}\left(\frac{X}{A}, \epsilon\right) \Phi_{1}(u ; \epsilon, \theta)+G\left(\frac{X}{A}, \epsilon\right) \Phi_{12}(u ; \epsilon, \theta)\right\}
\end{aligned}
$$

The matrix form of the equations above can be written as:

$$
\begin{aligned}
& {\left[\begin{array}{cc}
\left(\frac{X^{2}}{A^{3}}\right) G_{11}\left(\frac{X}{A}, \epsilon\right) \Phi(u ; \epsilon, \theta) & \left\{G\left(\frac{X}{A}, \epsilon\right)-\left(\frac{X}{A}\right) G_{1}\left(\frac{X}{A}, \epsilon\right)\right\} \Phi_{1}(u ; \epsilon, \theta)-\Gamma \\
\left\{G\left(\frac{X}{A}, \epsilon\right)-\left(\frac{X}{A}\right) G_{1}\left(\frac{X}{A}, \epsilon\right)\right\} \Phi_{1}(u ; \epsilon, \theta)-\Gamma & A G\left(\frac{X}{A}, \epsilon\right) \Phi_{11}(u ; \epsilon, \theta)
\end{array}\right]\left[\begin{array}{c}
\frac{\partial A}{\partial \epsilon} \\
\frac{\partial u}{\partial \epsilon}
\end{array}\right]} \\
& =\left[\begin{array}{c}
-\left\{G_{2}\left(\frac{X}{A}, \epsilon\right)-\left(\frac{X}{A}\right) G_{12}\left(\frac{X}{A}, \epsilon\right)\right\} \Phi(u ; \epsilon, \theta)-\left\{G\left(\frac{X}{A}, \epsilon\right)-\left(\frac{X}{A}\right) G_{1}\left(\frac{X}{A}, \epsilon\right)\right\} \Phi_{\epsilon}(u ; \epsilon, \theta) \\
-A\left\{G_{2}\left(\frac{X}{A}, \epsilon\right) \Phi_{1}(u ; \epsilon, \theta)+G\left(\frac{X}{A}, \epsilon\right) \Phi_{12}(u ; \epsilon, \theta)\right\}
\end{array}\right]
\end{aligned}
$$

We can then get the change in $A$ and $u$ as a result of a change in epsilon through Kramer's rule. The sign of the determinant in the numerator determines the sign of $\frac{\partial A}{\partial \epsilon}$ : 


$$
\begin{aligned}
&\left\langle-\left\{G_{2}\left(\frac{X}{A}, \epsilon\right)-\left(\frac{X}{A}\right) G_{12}\left(\frac{X}{A}, \epsilon\right)\right\} \Phi(u ; \epsilon, \theta)-\left\{G\left(\frac{X}{A}, \epsilon\right)-\left(\frac{X}{A}\right) G_{1}\left(\frac{X}{A}, \epsilon\right)\right\} \Phi_{\epsilon}(u ; \epsilon, \theta)\right\rangle \times \\
&\left\langle A G\left(\frac{X}{A}, \epsilon\right) \Phi_{11}(u ; \epsilon, \theta)\right\rangle- \\
&\left\langle\left\{G\left(\frac{X}{A}, \epsilon\right)-\left(\frac{X}{A}\right) G_{1}\left(\frac{X}{A}, \epsilon\right)\right\} \Phi_{1}(u ; \epsilon, \theta)-\Gamma\right\rangle \times \\
&\left\langle-A\left\{G_{2}\left(\frac{X}{A}, \epsilon\right) \Phi_{1}(u ; \epsilon, \theta)+G\left(\frac{X}{A}, \epsilon\right) \Phi_{12}(u ; \epsilon, \theta)\right\}\right\rangle
\end{aligned}
$$

The sign of the above equation becomes:

$$
\langle+\rangle \times\langle-\rangle-\langle-\rangle \times\langle+\rangle
$$

Thus, the sign of $\frac{\partial A}{\partial \epsilon}$ seems undetermined. In fact, it depends on the relative magnitudes of four terms: marginal effect of a drier climate on the marginal revenue of irrigated acres keeping irrigated acres and groundwater application per acre fixed (first term), marginal effect of a drier climate on the marginal revenue of groundwater application per acre keeping irrigated acres and groundwater application per acre fixed (last term), concavity of the profit function with respect to groundwater application per acre $\frac{\partial^{2} \pi}{\partial u^{2}}$ (second term), and cross partial derivative of the profit function $\frac{\partial^{2} \pi}{\partial u \partial A}$ (third term). However, we know that $\frac{\partial \lambda_{2}}{\partial \epsilon}<0$ so that as climate get drier, the switching point shifts to the right, i.e., irrigated acres for each well capacity decrease. This means that the magnitude of the interaction of the first two terms is greater than the magnitude of the interaction of the last two terms.

Similarly, for $\frac{\partial u}{\partial \epsilon}$, we have: 


$$
\begin{array}{r}
\left\langle\left(\frac{X^{2}}{A^{3}}\right) G_{11}\left(\frac{X}{A}, \epsilon\right) \Phi(u ; \epsilon, \theta)\right\rangle \times \\
\left\langle-A\left\{G_{2}\left(\frac{X}{A}, \epsilon\right) \Phi_{1}(u ; \epsilon, \theta)+G\left(\frac{X}{A}, \epsilon\right) \Phi_{12}(u ; \epsilon, \theta)\right\}\right\rangle- \\
\left\langle-\left\{G_{2}\left(\frac{X}{A}, \epsilon\right)-\left(\frac{X}{A}\right) G_{12}\left(\frac{X}{A}, \epsilon\right)\right\} \Phi(u ; \epsilon, \theta)-\left\{G\left(\frac{X}{A}, \epsilon\right)-\left(\frac{X}{A}\right) G_{1}\left(\frac{X}{A}, \epsilon\right)\right\} \Phi_{\epsilon}(u ; \epsilon, \theta)\right\rangle \times \\
\left\langle\left\{G\left(\frac{X}{A}, \epsilon\right)-\left(\frac{X}{A}\right) G_{1}\left(\frac{X}{A}, \epsilon\right)\right\} \Phi_{1}(u ; \epsilon, \theta)-\Gamma\right\rangle
\end{array}
$$

and the sign of the above equation becomes:

$$
\langle-\rangle \times\langle+\rangle-\langle+\rangle \times\langle-\rangle
$$

We know that from Equation 27, where $A=1$ is constant, a marginally drier climate results in an increased groundwater application. For well capacities below the switching point where both $A$ and $u$ are allowed to change, and $A$ decreases, $\frac{X}{A}$ increases. An increase in $\frac{X}{A}$ would suggest a further increase in groundwater application per acre. All in all, this suggests that when both irrigated acres and application per acre can change, irrigated acres may decrease while application per acre may increase.

\section{Sensitivity Analysis}

This section shows the shift in the switching point as a result of changes in different parameters. The figure below shows the effect of changes in the price of corn, pumping costs, per acre (fixed) costs, and $\theta$ on total seasonal groundwater application. The figures show that an increase in the price of corn will shift the switching point to the left, due to an increase in the number of acres that is irrigated for each well capacity. This is because revenue per acre 
increases with higher output prices. On the other hand, an increase in the cost of pumping or fixed costs of irrigation has an opposite effect on the profits per acre and will shift the switching point to the right. An increase in $\theta$ mainly affects demand for groundwater through changes in intensive margin application as is clear by the $\Phi($.$) function. As a result, it has$ small effects on the switching point. The curvature of the total water use is also sensitive to the changes in parameters. This is mainly because both $u_{\infty}^{*}$ and $u^{*}$ for well capacities below the switching point change as a result of a change in these parameters. The change in the curvature depends on the changes in intensive margin application. When the change does not affect the intensive margin application, e.g., in the case of changes in fixed costs, the curvature does not change and only the switching point shifts to the right. The intuition is that under some conditions, e.g., greater price of output, while the switching point shifts to the left and more acres are irrigated at every well capacity, there are adjustments on the intensive margin that take place to reduce groundwater application per acre. 

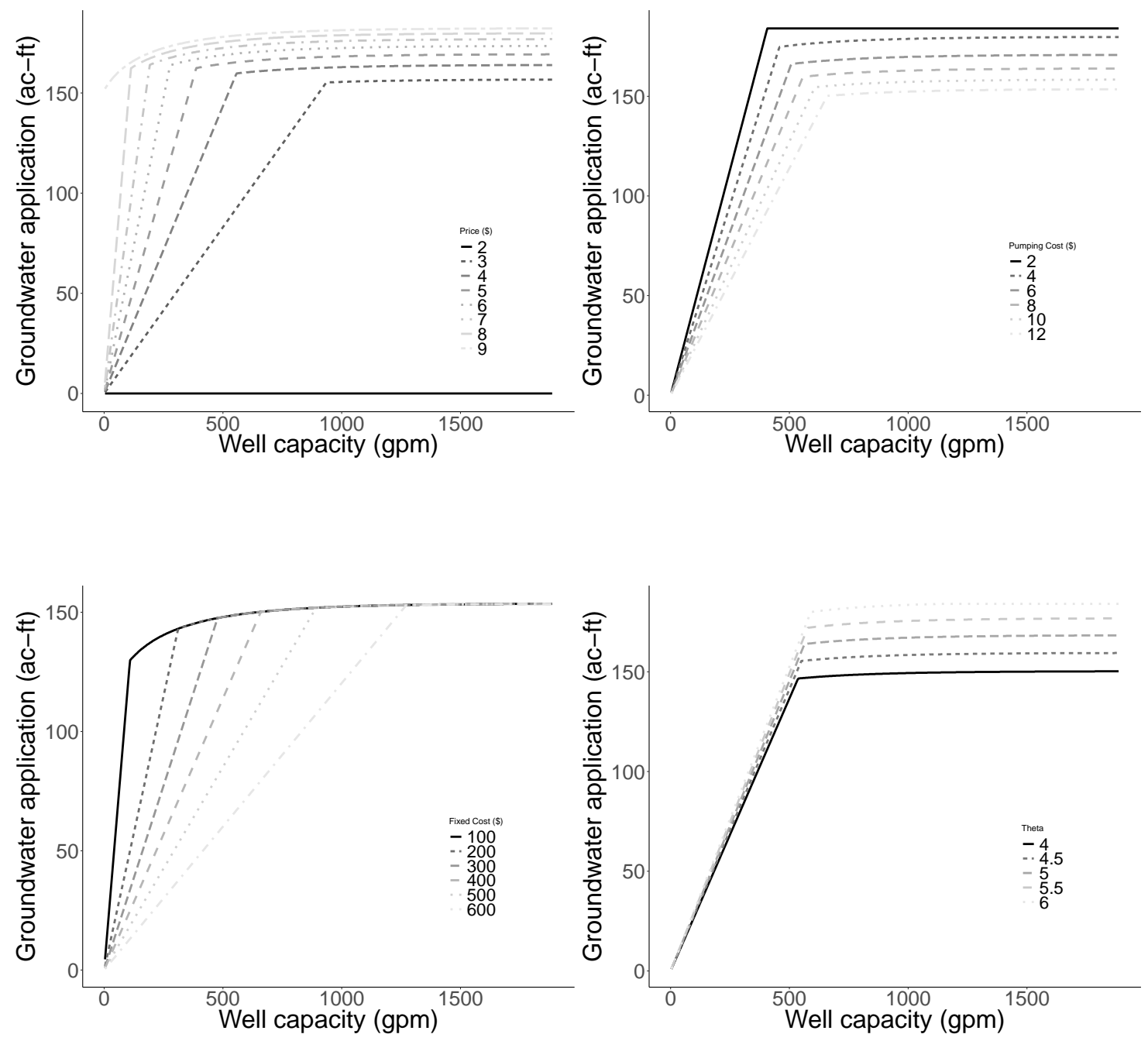

Figure 8: Profit-maximizing levels of seasonal groundwater application under different levels of instantaneous groundwater availability (well capacity) for different prices of corn (top left), pumping costs (top right), per acre (fixed) costs (bottom left), and $\theta$ (bottom right)

Finally, while we have considered a constant marginal pumping cost across well capacities, as mentioned in Section 2, pumping costs are negatively correlated with well capacity such that higher well capacities have lower pumping costs. Thus, we have considered the following relationship: pumping $\operatorname{cost}(\$ / a c-i n)=11.5-0.1 \times$ well capacity $($ af $/$ day $)$. This relationship was chosen to keep the average pumping cost equal to $\$ 8$, the same as the amount assumed in the analysis in the main body of text while providing higher pumping costs for lower well capacities. The figure below shows that changing pumping costs can shift the switching point slightly to the right and affect water use for different well capacities. The exact shift in the 


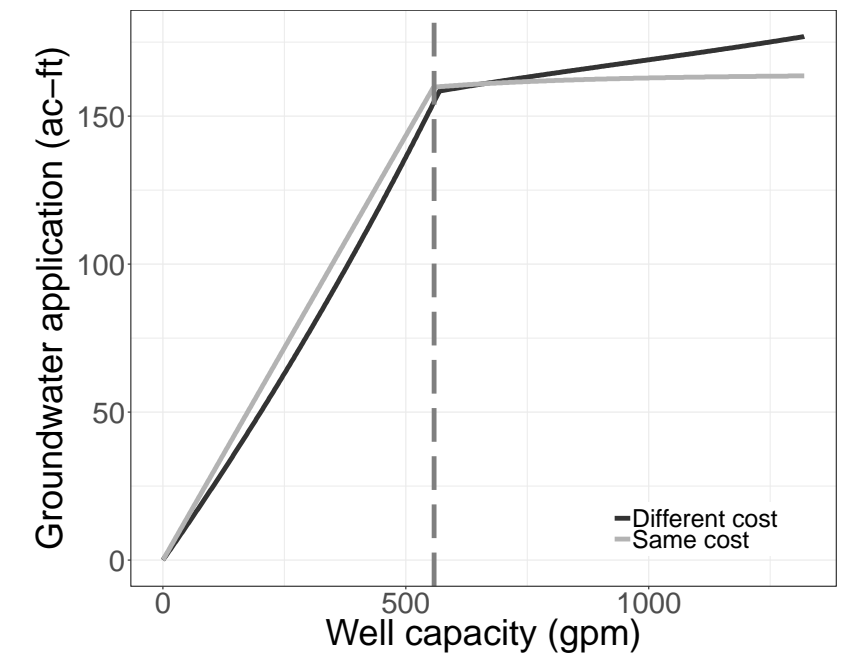

Figure 9: Profit-maximizing seasonal groundwater use under constant pumping cost across well capacities (grey line) and under heterogenous pumping costs across well capacities (black line). 